\title{
Leyes de Comunidades Autónomas sobre Universidad
}

Jesús M. de Miguel*

España experimenta un nuevo proceso de reforma del sector universitario ${ }^{1}$. Tras la LOU - una ley para toda España- toca el turno al diseño de las leyes de educación superior de las diecisiete Comunidades Autónomas, así como la elaboración de los Estatutos de las universidades. La ley sobre universidades de la Comunidad Autónoma catalana -conocida como LUC (Llei d'Universitats de Catalunya) ${ }^{2}$ - se aprueba el 19 de febrero de 2003. Consta de 165 artículos y 23 disposiciones. En el año 2001, durante la elaboración de la Ley Orgánica de Universidades (LOU) se criticó el que fuera extensa y reglamentista; pero la primera Comunidad Autónoma que aprueba su ley tiene un $85 \%$ más artículos que la LOU y en algunos extremos es más reglamentista. La explicación es que hay artículos que son repetitivos de la LOU, son obvios, o sencillamente reproducen la legislación que se aplica a todas las universidades españolas. También se incluyen objetivos innecesarios sobre los acuerdos internacionales entre el Gobierno español y la Unión Europea en materias de convergencia sobre el European Area of Higher Education. Es un texto legal que en algunos extremos -como la estructura del Consejo Social, las funciones del Consejo Interuniversitario de Cataluña, o las prerrogativas del Gobierno autonómico- resulta detallado. ${ }^{3}$

Se estructura en títulos, capítulos, secciones, y artículos. Un esquema de su contenido aparece a continuación. (Entre paréntesis se señalan los artículos que abarca cada epígrafe). Los asteriscos * señalan los temas en que considero que la ley es más innovadora.
1. Preámbulo

Historia 1300-2000

Catalanismo político

Área Europea de Educación Terciaria

Resumen de la ley

2. Generalidades

Sistema universitario (1-2)

Objetivos (3)

Principios (4-5)

Lengua (6)

3. Objetivos

Educación

Titulaciones (7-14)

Área europea (15-17)

Docencia (18-19)

Investigación (20-28)

4. Capital humano

Comunidad universitaria (29-31)

Estudiantes (32-41)

Profesorado (42-43)

* Profesores contratados (44-58)

* Investigadores (59-63) 
Condiciones de trabajo (64-67)

Becarios y ayudantes (68-70)

Retribuciones del personal contratado (71-72)

PAS (73-76)

5. Estructura de las universidades públicas

Órganos de gobierno (77-78)

Rector (79)

Gerente (80)

${ }^{*}$ Consejo Social (81-98)

Consejo de antiguos alumnos (99-100)

6. Relaciones del gobierno autonómico con las universidades

Régimen jurídico (101-102)

Estatutos (103)

Competencias del gobierno autonómico (104-114)

7. Planificación (115)

Programación (116)

Financiación (117-120)

8. Coordinación

${ }^{*}$ Consejo Interuniversitario de Cataluña (121-126)

Conferencia General (127-128)

Junta (129-133)

Organización (134-136)

9. Evaluación

* Agencia para la Calidad -AQSUC- (137-143)

Comisión de Evaluación de la Calidad (144)

Comisión de Profesorado Contratado (145)

Comisión de Evaluación de la

Investigación (146-148)

Organización (149-154)

10. Financiación de las universidades públicas

Patrimonio y contratación (155-160)

Presupuesto (161-165)

12 Disposiciones adicionales

Oficina europea (4a)

UOC (6a)

ICREA ( 9 a)

7 Transitorias

1 Derogatoria

*3 Finales

Este esquema de la LUC se analiza a continuación, incluyendo una interpretación de las innovaciones y estructura que plantea. También se explican los problemas que crea, así como los aspectos olvidados. Desde el principio, la Ley de Universidades de Cataluña establece como objetivo prioritario de las once universidades en esa Comunidad Autónoma "el fomento del pensa- miento crítico" (artículo 3.b). Lo que sigue es un análisis sociológico con ese objetivo ${ }^{4}$.

\section{Situación actual de la Universidad}

Con 6,21 millones de habitantes Cataluña tiene once universidades: siete públicas, dos semipúblicas -Oberta de Catalunya y Vic- y dos privadas5. De las públicas cuatro están en la ciudad de Barcelona, y las otras tres una en cada provincia. Las dos privadas son católicas, y la Universidad Internacional de Cataluña de influencia Opus Dei. Las universidades privadas imparten docencia al $12 \%$ de los estudiantes universitarios de la Comunidad Autónoma. Eso supone un sector universitario que está el doble de privatizado que la media española. La antigüedad media de las once universidades es de 65 años, con diferencias importantes entre ellas. La universidad más antigua proviene del año 1450 y la más moderna es del año 1997.

Los estudios sociológicos indican que el modelo universitario en Cataluña es más elitista que en el resto de España, y menos universalista. A pesar del discurso dominante, la Universidad en Cataluña ha supuesto una estrategia de reproducción social de las clases medias y altas más que un sistema de movilidad social ascendente neta. La población inmigrante del resto de España explica el acceso limitado a la Universidad. Cataluña representa el 15\% de la población española, pero a pesar de su desarrollo económico tiene solamente un $13 \%$ de los/as estudiantes universitarios. Es una Comunidad Autónoma rica, con un PIB per capita que es un $21 \%$ más alto que el total de España. Pero la Universidad no parece haber jugado un papel central dentro de la sociedad. Quizás se deba a que es una región en que la industrialización ha sido importante. La proporción adulta - 16 y más años- con estudios terciarios es $15,1 \%$, bastante inferior a la Comunidad de Madrid (cuya proporción es un 48\% más alta) e incluso menor que la media de España que es $15,3 \%$. Pero eso no se debe solamente a la industrialización, pues el País Vasco tiene una proporción de población adulta con estudios universitarios que es un $46 \%$ más alta que Cataluña. En otras zonas ricas, la Comunidad Foral de Navarra tiene un 34\% más de población con estudios universitarios que Cataluña. La tasa de estudiantes universitarios por población en Cataluña es solamente el $85 \%$ de la media española (tasa de 33 estudiantes por mil habitantes). Todos los indicadores sugieren que la Universidad no es una institución central en la sociedad catalana, y que la formación postsecundaria de la población es reducida y desigual. Cataluña no ha ido incorporando a la población inmigrante a la Universidad en la proporción que debiera. La tasa del 15\% de población con estudios universitarios debería pues incrementarse lo antes posible. Elevar la calidad de la educación universitaria, y sobre todo extenderla a una proporción mucho mayor de la población, son las dos asignaturas pendientes de la Universidad en Cataluña. La LUC debería haber propuesto soluciones a esta situación caren- 
cial. Pero se centra demasiado en el profesorado, a pesar de ser uno de los indicadores mejores de las universidades catalanas: tiene un $16 \%$ del profesorado universitario de España para el $13 \%$ del alumnado universitario.

Las universidades catalanas, con 7,7 profesores por cada cien estudiantes universitarios, tienen una tasa de profesorado que es un $28 \%$ más alta que la media española. Es una tasa más elevada incluso que la Comunidad de Madrid, un $43 \%$ más que en el País Vasco, 24\% más que en la Comunidad Valenciana, y un $30 \%$ mayor que en Aragón. A niveles relativos se puede considerar que en Cataluña hay un exceso de profesores universitarios. También hay una situación favorable de personal de administración y servicios (PAS), salvo que en el contexto español la tasa de PAS en relación al alumnado y profesorado es muy baja. Cataluña cuenta con buenos recursos universitarios para una población estudiantil reducida. Las bibliotecas tienen una media de 24 libros por estudiante, un 45\% más elevada que la media española. Otro problema es que la proporción de estudiantes en carreras cortas -diplomaturas e ingeniería técnica- (40\%) está por encima de la media de España. Eso va a complicar el proceso de convergencia dentro del Área Europea de Educación Terciaria al desaparecer esos títulos intermedios. ${ }^{6}$ Otros procesos suponen a veces un cierto retraso, sobre todo en la proporción de profesores mujeres (34\%) que es igual a la media, pero que en el marco de referencia de abundancia de recursos universitarios supone uno de sus puntos flacos. La LUC establece la igualación por género (disposición adicional $8^{\mathrm{a}}$ ), pero no propone medidas para superar la situación discriminatoria existente en el profesorado y en los cargos académicos.

Al no ser una institución central, y haber pocos estudiantes universitarios, las universidades tienen bastantes recursos estructurales y de capital humano. Así se explica que la productividad sea mejor que en otras Comunidades Autónomas, pero que al mismo tiempo la discriminación (de familias inmigrantes y de clases bajas) sea mayor. ${ }^{7}$ Proporcionalmente hay un 20\% más de estudiantes que terminan la carrera en los años justos que la media española. La producción de títulos de doctor es incluso más elevada: un $26 \%$ más alta que la media española. Lo que puede parecer una ventaja es quizás un problema, pues en España hay plétora de doctores. ${ }^{8}$ En Cataluña la bolsa de doctores sin empleo en la Universidad es creciente. Cada año se producen 4,8 nuevos títulos de doctor por mil estudiantes universitarios; es el doble que la productividad del País Vasco. Si el sector privado no contrata más investigadores -y no lo está haciendo- los problemas van a ser crecientes. La reforma del doctorado es imperiosa; otro aspecto que la LUC no soluciona.

Las universidades catalanas tienen globalmente un nivel de calidad alto, aproximadamente un $14 \%$ más alto que la media española. Sólo las universidades de la Comunidad Foral de Navarra o las de la Comunidad de Madrid son mejores. El retra- to robot de la Universidad en Cataluña es una institución doblemente periférica, y tradicionalmente elitista. Debe desarrollar más la educación postsecundaria de la población. Cuenta para ello con medios suficientes, sobre todo de profesorado, y con una productividad adecuada que debe mantener. No tendría que aumentar la tasa de profesorado, pero sí la de PAS. El objetivo fundamental debería ser la extensión de la enseñanza universitaria a las clases bajas de la población, que en mayor medida son castellano-parlantes, y cada vez más inmigrantes de fuera de la Unión Europea. Es posible que si se mantienen las tasas de producción de doctores se produzcan problemas de contratación de investigadores. En resumen, la Universidad en esta Comunidad Autónoma es una institución periférica, relativamente aislada de la sociedad, y con una tendencia a aislarse aún más. Es una institución elitista que no se ha abierto todavía a la población económicamente más necesitada, sobre todo a la inmigrante del resto de España y de países menos desarrollados. Esa estructura no se está superando pues el proceso de privatización es el doble que la media española, y creciente. Se necesitaría además una política de becas enérgica. La LUC no soluciona esos problemas, o desvía la atención hacia temas menos problemáticos.

La ley pone bastante énfasis en promover el personal investigador. En la Comunidad Autónoma el gasto en I+D per capita es alrededor de $203 €$ anuales, un $43 \%$ más alto que la media española. Pero la tasa de investigadores no es elevada, aunque con sus 24 investigadores por diez mil habitantes es un 25\% más alta que la media de España. Sin embargo, el papel de la Universidad en la investigación catalana es marginal: apenas supone un 24\% del gasto interno total en $\mathrm{I}+\mathrm{D}$, cuando la media nacional es del $30 \%$. Las universidades concentran un poco más de la mitad de los/as investigadores de la Comunidad Autónoma, un porcentaje similar al total de España. Esto supone un gasto en I+D aproximadamente de $1.477 €$ por estudiante universitario al año, es decir, un 38\% más que la media española. La tasa de investigadores por cien estudiantes, ambos en la Universidad, es 3,8. Esta es una tasa un $41 \%$ superior a la media española. Los indicadores son consistentes y sugieren que tanto los recursos de investigación como la proporción de investigadores es adecuada en Cataluña. Se requiere una expansión en $\mathrm{I}+\mathrm{D}$ para igualarse a la situación europea o norteamericana, pero a nivel español es un sector no excesivamente problemático.

El problema principal de la Universidad catalana es que es una institución todavía elitista, periférica, y algo aislada dentro de la sociedad. Mantiene desde décadas un modelo de clases altas y medias, que repercute en una población con pocos estudios postsecundarios. A pesar del tono del preámbulo de la LUC, no hay motivo para sentirse especialmente orgulloso de un modelo universitario que es menos universalista y democrático que en el resto de España. Los recursos que utiliza son abundantes, especialmente profesorado y personal investigador. Por eso el incremento de profesorado que propone la LUC es un objetivo inadecuado. Es 
una Universidad con un déficit democrático pues no ha incorporado a las clases más bajas de la sociedad, y mantiene una estratificación social desigual excesiva. En este sentido no es un modelo de Universidad para una sociedad avanzada. La población pendiente de integrar en la Universidad es en parte castellano-parlante, lo que va a requerir una tolerancia mayor en la política lingüística. Son urgentes programas de becas efectivos precisamente para esas clases más bajas. También falta un estudio serio de la Universidad catalana, así como una evaluación externa de la política universitaria llevada a cabo en los últimos años.

\section{Innovaciones de la ley catalana}

Los problemas fundamentales del sector universitario en esta Comunidad Autónoma son fundamentalmente cinco: (a) extensión de los estudios universitarios al 85\% de cada cohorte de jóvenes, (b) duplicar el presupuesto público per capita en educación terciaria; (c) expandir numéricamente y elevar las condiciones salariales del PAS, (d) incrementar sustancialmente las becas a estudiantes, tanto en proporción de estudiantes como en cuantía de becas; y (e) organizar un doctorado de calidad y eficaz, con una productividad cinco veces superior a la actual. La ley no se plantea estos problemas reales. La LUC sufre de una cierta indefinición, ambigüedad como señalan otras personas ${ }^{9}$, y en general confusión respecto de los problemas fundamentales. Mantiene un planteamiento fundamentalmente conservador.

La LUC es innovadora en algunos aspectos: (a) la reforma de contratación de profesorado permanente a niveles altos en el escalafón, como catedráticos y agregados; (b) una definición detallada de los Consejos Sociales de las universidades solicitada por la LOU; (c) un Consejo Interuniversitario de Cataluña como alternativa al Consejo de Coordinación Universitaria español; y (d) la re-creación de una Agencia para la Calidad del llamado "sistema universitario" de Cataluña como alternativa a la ANECA. Establece parcelas de poder autonómico, en parte previstas en la LOU y en otra parte paralelas a la administración central. Hay otros aspectos en que se esperaba que la ley podía innovar pero que por alguna razón no hace: (1) potenciar la autonomía a las universidades; (2) institucionalizar la figura jurídica del "Grupo de Investigación" y también del Departamento; (3) diseñar un tercer ciclo como estudios regulares que incluyan el master y el doctorado, ambos de calidad; (4) estratificar las universidades según especializaciones diseñando unas más docentes y otras más investigadoras; y (5) potenciar una reforma de estudios institucionalizando una educación generalista inicial.

La ley es larga, suficiente para gobernar el sector universitario en la Comunidad Autónoma, sin que sea necesario tener en cuenta otra legislación de la Administración central. Hay artículos cuyo contenido es repetitivo de la LOU, y otros cuyo conte- nido es obvio. Se esperaba la primera ley de una Comunidad Autónoma para medir el nivel de colaboración que cada Comunidad Autónoma piensa establecer con las otras dieciséis Comunidades Autónomas y con la Administración Central. Desgraciadamente esta primera ley autonómica no plantea prácticamente ningún nivel de colaboración. Salta de una organización exclusiva para su propia Comunidad Autónoma a la colaboración con "Europa" y con "el mundo". No hay referencias a otras Comunidades Autónomas, ni se prevé la colaboración (ni siquiera en temas tan obvios como recursos de bibliotecas o investigadores). No cita la palabra "España" ni una sola vez en toda la ley. Para evitar cualquier referencia, la LUC muestra un fervor europeísta; en un esfuerzo típico de misplaced concreteness. Por lo que respecta al sector universitario la integración en el llamado Proceso de Bolonia deriva de tratados firmados por el Gobierno español, que es el que además tiene la responsabilidad de reglamentar y desarrollar esa convergencia antes del año 2010. Que una Comunidad Autónoma pueda liderar esa convergencia por su cuenta, cuando depende de tratados internacionales oculta una cierta insolidaridad con el resto de Comunidades Autónomas, tan importante en el sector universitario. La ley plantea un aislamiento de Cataluña en materias de sector universitario que resulta perjudicial para su población.

La divergencia entre la Cataluña real (los problemas que de verdad tiene el sector universitario en esa Comunidad Autónoma) y la Cataluña ideal (la legislación autonómica) deriva de que la ley está promulgada por un gobierno autonómico conservador y nacionalista, poco interesado en hacer accesible la Universidad a más población, en lograr la autonomía universitaria, o en conseguir una Universidad crítica, de calidad. ${ }^{10}$ El empeño más importante de la ley es crear un "sistema universitario catalán" que depende del Gobierno autonómico. El control que se plantea por parte del Gobierno (de la Comunidad Autónoma) sobre las once universidades, y las instituciones que gobiernan por encima de las universidades es considerable. La mayor parte de los miembros de las instituciones controladoras son nombrados a dedo, directamente, por el propio Gobierno de la Generalitat: el 62\% de la Junta Permanente del Consejo Interuniversitario de Cataluña, o el 59\% del Consejo de Dirección de la Agencia para la Calidad. La LUC establece además una casuística detallada de funciones y prerrogativas de las instituciones que están por encima de las universidades, que es extensa. La mayor parte de la ley está dedicada a establecer el poder del Gobierno de la Generalitat. Las universidades, individualmente, apenas conservan poder. Los rectores, que según la LOU, iban a tener un rol de liderazgo y de gobierno efectivo de sus universidades, ven disminuidas drásticamente sus funciones y poderes en esta Comunidad Autónoma. El poder se concentra en consejos, agencias, y comisiones colegiadas, que se solapan mucho, y que controlan de forma efectiva la planificación y gestión universitaria. Con ello se logra una combinación difícil de lograr en política democrática: detentar el poder pero difuminar 
(o incluso evadir) la responsabilidad política. Los responsables de la política universitaria real -Presidente de la Generalitat, y consejeros o ministros, especialmente el de Universidad (o como se denomine) - toman realmente decisiones, pero no pueden ser declarados responsables dado que las decisiones finales son tomadas por organismos colegiados que el propio Gobierno nombra y controla en una proporción alta.

La medida de creación de nuevos tipos de profesorado, incluyendo plazas de profesor permanente a nivel catedrático, y el anuncio (en las disposiciones finales de la propia ley) de la dotación -al 50\% del costo- de 1.200 plazas de profesores permanentes, sirve para acallar las críticas del profesorado, que es quien realmente gobierna en la Universidad actualmente. En cualquier caso, esta promesa supone en el año 2015 apenas un 7,5\% del profesorado, siempre y cuando las universidades accedan al costo del $50 \%$ restante. Con esta cantidad a doce años, el ritmo de dotación de catedráticos sería de cuatro catedráticos por universidad al año. Es una cantidad que obviamente no va a transformar las estructuras actuales del profesorado. Pero políticamente es un anzuelo para las personas que esperan desde hace años ingresar en un "cuerpo de catedráticos" sin tener que realizar un concurso. Esta disposición final de la ley es lo más realista que se ofrece en términos prácticos.

\section{Preámbulo}

El preámbulo define una figura sin personalidad jurídica que denomina "sistema universitario de Cataluña" y que supuestamente incluye todos los recursos públicos y privados, tanto en educación como en investigación académica. Lo define como la "existencia de una realidad universitaria catalana que parte de una tradición intelectual, educativa y científica que es propia”. Declara que es "voluntad de esta realidad [sic] integrarse plenamente en el espacio europeo de enseñanza superior y de conseguir un papel protagonista en su construcción". La expresión "voluntad de una realidad" no se entiende. Plantea la convergencia con Europa -con el llamado Espacio Europeo de Enseñanza Superior- o Proceso de Bolonia sin hacer referencia a que es un tratado internacional firmado por el Gobierno español, y que debe ser liderado por el Ministerio de Educación. Es además difícil plantear a estas alturas (con un retraso evidente en su implicación) un papel protagonista de ese proceso de europeización de la Universidad. Luego más humildemente reconoce que se limita a crear "una oficina sobre el espacio europeo" dentro del Consejo Interuniversitario de Cataluña, como "observatorio de tendencias en esta materia, y promotora de la adaptación de las universidades catalanas a este espacio". Esto es más realista que hablar de "papel protagonista" a nivel de tratados internacionales. Al tema vuelvo aquí cuando la LUC plantea operativamente ese protagonismo en el articulado de la ley.

Los preámbulos suelen ser altisonantes y barrocos, y a menudo no coinciden luego con la normativa de la ley. El preámbulo tiene un tono victimista esperable. La razón que -según la LUCexplica la falta de una Universidad catalana universalista de calidad, desde el año 1300 hasta el siglo XXI, es siempre externa a Cataluña. Presenta a la Universidad en Cataluña como un todo homogéneo: "en la resistencia contra el franquismo, destaca el papel de la universidad como un espacio de reivindicación democrática y pacifista de las libertades y de afirmación de sus funciones sociales". Especifica que sólo con la Generalitat de Cataluña -se entiende entonces gobernada por Convergencia i Unió- se consolida una universidad propia, catalana, científica y democrática. Es contradictorio, porque el pasado antifranquista de la Universidad está basado en posiciones políticas progresistas, mientras que la LUC es obra de un gobierno conservador. El tono progresista del preámbulo no coincide luego con el texto de la ley; incluso parece escrito por una persona distinta. El proceso culmina -según la LUC- con la creación del Departamento de Universidades, Investigación y Sociedad de la Información (DURSI) en abril del año 2000. Se afirma que la LUC es heredera "de la dilatada e intensa tradición universitaria de Cataluña". La realidad es que Cataluña tiene una tradición universitaria débil, con una proporción de población, y de estudiantes universitarios, más baja de lo esperable. Lo que llama la atención en los estudios serios sobre ese sector universitario, es la poca importancia y atención que se pone a la Universidad en esta Comunidad Autónoma, así como su elitismo. A pesar de esa realidad, que la ley debería de haber enfocado con realismo, la LUC explícitamente "reivindica el catalanismo político como inspiración para la creación de un marco propio de enseñanza superior". Pero luego no habla de enseñanza superior, sino que reglamenta la enseñanza universitaria olvidándose de la enseñanza superior no universitaria. Esto no es un defecto formal, puesto que la LUC se denomina explícitamente "ley de universidades", ni siquiera "ley de Universidad". Pero el olvido de todo lo que es enseñanza superior no universitaria es un problema que no resuelve.

La LUC es contradictoria cuando en su preámbulo afirma que la ley "pretende contribuir a la construcción de un sistema universitario profundamente universalista" cuando luego no hay un solo artículo que proponga la extensión del sistema universitario a la mayor parte de la población, ni propone medidas para reducir el elitismo de la Universidad. Ese es uno de los fallos fundamentales de la LUC. Cita luego una propuesta de un congreso universitario del año 1918 que señala el deseo de que la Universidad "tienda a aportar el esfuerzo y el espíritu del pueblo catalán al patrimonio espiritual de la Humanidad" (sic). SSe supone que la LUC refrenda esta idea? Luego explica que la ley es el resultado de una reflexión larga sobre la Universidad, citando varios informes entre 
ellos el Informe Universidad 2000, y el de Por un nuevo modelo de Universidad, aunque luego la LUC no sigue sus recomendaciones. ¿Por qué no tiene en cuenta otros estudios españoles más serios y científicos? El distanciamiento con las otras Comunidades Autónomas, y con la Administración Central, es prevalente a lo largo de toda la ley. Sólo hacia el final del preámbulo -y casi de pasada- admite que la LUC se inserta en el marco básico de la LOU. Obviamente no podría ser de otra manera, sobre todo teniendo en cuenta que el partido del Gobierno autonómico (CiU) votó a favor de la LOU en diciembre de 2001.

La propia LUC reconoce lo que tiene de innovadora: "uno de los aspectos de más novedad de esta Ley es la regulación del profesorado contratado. Se abre una nueva vía de carrera académica, que puede ser complementaria o sustitutiva pero no menos exigente que la funcionarial, basada en la contratación laboral". No puede ser sustitutiva cuando sólo puede alcanzar, y eso dentro de doce años, al 7,5\% del profesorado. Añade que "eso está en consonancia con una reivindicación histórica de los movimientos catalanes de reforma universitaria”. Según la legislación española actual en las Universidades hay un 50\% de profesorado contratado. Es la propia LOU quien propone la figura de los "profesores contratados doctores" (artículo 52) estableciendo los requisitos. No es pues ninguna innovación de la LUC. Quizás lo único nuevo es que a un 33\% de ellos/as se les denomina confusamente con el mismo título que al de un cuerpo de funcionarios: "catedrático". Pero a la larga esa coincidencia de denominación va a crear más conflictos y sinsabores que beneficios. ${ }^{11}$ Por otro lado, esta fórmula de contratación puede ser asumida por otras Comunidades Autónomas sin necesidad de "reivindicaciones históricas".

Hay un tono moderno en la LUC al incorporar expresiones y conceptos como educación superior a lo largo de la vida (lo que se conoce como LLL), el Espacio Europeo, o los términos de "calidad" y "excelencia" tan de moda actualmente. La LUC es además cuidadosa de referirse siempre a los dos géneros: estudiantes y estudiantas, investigadores e investigadoras, profesores y profesoras, rector o rectora, y así en todo el texto.

\section{Generalidades}

La LUC inventa un concepto que es más una romantización de la realidad que una verdadera institución: "el sistema universitario de Cataluña" que incluye las once universidades privadas y públicas. Entre los objetivos, la LUC plantea la Universidad como transmisora y creadora de valores humanos: pensamiento crítico, libertad, igualdad, solidaridad, pluralismo, democracia, e incluso desarrollo sostenible. Otro objetivo fundamental de la Universidad es la incorporación de la lengua catalana a todos los ámbitos del conocimiento. La forma en que se plantea el bilingüismo en el artículo 6 tiene una redacción peculiar: "El catalán es la lengua oficial de las universidades de Cataluña, asi como también lo es el castellano" (sic). Lo correcto sería haber escrito: "Las dos lenguas oficiales de la Universidad son el catalán y castellano". No vuelve nunca más a hablar del uso de castellano como lengua oficial. Señala que "el catalán es la lengua propia de las universidades de Cataluña y, por tanto, es la lengua de uso normal de sus actividades". Hay que estimular el conocimiento y el uso del catalán. Los/as profesores (a excepción de los profesores visitantes) han de conocer suficientemente las dos lenguas oficiales. Se garantiza también que en los procesos selectivos de acceso de profesorado y de evaluación de la actividad docente/investigadora se concrete ese conocimiento "suficiente". Se procura además que el acceso y la incorporación de nuevos estudiantes, profesores y PAS "no altere los normales usos lingüísticos docentes". No queda claro lo que la ley entiende por "alterar" ni por "normales". El tema de las dos lenguas oficiales es ambiguo y difuso en la LUC, haciendo referencia a legislación anterior, sin solucionar problemas nuevos en el acceso de la población económicamente más desfavorecida e inmigrantes.

Entre los principios informadores reconoce lo que ya señala la LOU sobre autonomía universitaria, asumiendo la "libertad plena de libertad de organización y funcionamiento, con capacidad de autogobierno" de las universidades. Luego en la práctica la LUC recorta mucho esa autonomía. También propone el "principio de igualdad de oportunidades" (con la misma expresión de la legislación sobre el PIO previa a 1975) en el acceso y la permanencia en la Universidad para todos los ciudadanos, lo que en realidad no se cumple. ${ }^{12}$ Otro principio es el de aprendizaje a lo largo de la vida, que se justifica por el objetivo de "mejorar la cohesión social, la igualdad de oportunidades y la calidad de vida". No queda claro lo que significa la expresión "mejorar la cohesión social" ni cómo se va a conseguir. En el artículo 5 repite otra vez los valores humanos que deben informar la educación terciaria: libertad, responsabilidad, convivencia, solidaridad, participación y ciudadanía plena. Aquí olvida el principio de igualdad así como el pluralismo y la crítica mencionados antes. La idea de ciudadanía es innecesaria, a menos que se refiera a derechos básicos de la población, no necesariamente de los ciudadanos.

\section{Objetivos}

La LUC define la "actividad universitaria" como educación e investigación únicamente. Dentro de educación diferencia estudio de docencia. Se establece el concepto de "titulaciones transver- 
sales" tanto en las universidades públicas como en las privadas, aunque no queda claro cómo se organizan. Los estudios de doctorado se resumen en un artículo (el $12^{\circ}$ ) que no ofrece innovación alguna. Eso es llamativo, pues el doctorado es uno de los problemas que requieren una reforma más perentoria. Se esperaba que la Generalitat reglamentase ese tipo de estudios. Iguala el doctorado más a formación de personal investigador que al proceso de avance del conocimiento. Sólo un frase llama la atención, cuando señala que hay que "potenciar el acceso a los estudios de doctorado de los/as estudiantes mejor preparados, sea cual sea su nacionalidad o procedencia”. Eso es obvio, pero el hecho de señalarlo explícitamente supone una cierta vocación internacionalista. Curiosamente no se dice lo mismo en las carreras (licenciatura o ingeniería) que también debería ser obvio. El resto es información innecesaria o redundante. ${ }^{13}$

La convergencia con el sistema universitario europeo supone la desaparición de los título de diplomatura e ingeniería técnica. La LUC no plantea directamente este problema, pero señala que este cambio podría realizarse mediante el diseño de "títulos propios" de las universidades. Pero obviamente esa no va a ser la solución que se va a adoptar en España. El artículo es confuso sobre lo que realmente propone. Parece sugerir que las diplomaturas se transformen en títulos propios, pero no se sabe si se refiere exactamente a esa estrategia. Lo normal es que se conviertan en licenciaturas.

Se asume la moda del lifelong learning (LLL), traducido como "educación superior a lo largo de la vida". Pero el artículo 14 al respecto no presenta ideas concretas. Según la ley, es el Gobierno de la Generalitat quien tiene que "velar para que las universidades ofrezcan programas adecuados". La LUC se equivoca al mencionar que es un elemento del Espacio Europeo, cuando realmente es un proceso mundial, poco desarrollado en Europa. La mención continua al "Espacio Europeo" parece más bien una excusa para introducir conceptos, cuando en realidad no son innovaciones europeas. Lo importante es articular y desarrollar la educación superior, primero para toda la población, y luego durante toda la vida de esa población. No se trata de crear educación permanente sólo para las clases medias y altas. La LUC pierde aquí la ocasión de impulsar un diseño progresista y universalista de educación superior.

Se dedican tres artículos específicos (del 15 al 17) al llamado "Espacio Europeo de Titulaciones". Se señalan las medidas ya firmadas por España en los tratados europeos: suplemento o apostilla al título, el sistema de dos ciclos, denominación de títulos, crédito europeo (ECTS), y adaptación del sistema de calificaciones. Son medidas ya conocidas, sin ninguna innovación adicional. Es parte del proceso de adecuación de todas las universidades españolas para hacerlas compatibles con el ámbito europeo. El artículo 17 de la LUC señala que es el Consejo Interuniversitario de Cataluña quien coordinará ese proceso.
Tendría que haber especificado que es coordinado realmente por la Administración Central de acuerdo con la LOU y con el resto de legislación a nivel de toda España. El proceso de convergencia con Europa requiere diferenciar lo que son medidas obvias de homologación, de los problemas de fondo que superan la responsabilidad de una Comunidad Autónoma concreta. En el epígrafe siguiente se explican esos problemas.

En el apartado de docencia (artículo 18 y 19) la LUC no aporta nada nuevo. Ni siquiera desarrolla la enseñanza virtual o a distancia. El articulado sobre investigación es más detallado y progresivo (artículos 20 a 28). Se refiere al avance del conocimiento mediante cuatro procesos: formación investigadora, investigación, innovación tecnológica, y transferencia. El Gobierno de la Generalitat impulsa la investigación catalana en el Espacio Europeo. Eso es obvio, pero la investigación no se debe reducir a Europa, sino a un contexto de colaboración intensa con el resto de España (algo que la LUC nunca admite por escrito) y a nivel mundial. De nuevo la cita a la colaboración con Europa -y nunca con las otras dieciséis Comunidades Autónomas- es ilógica cuando se habla de investigación científica. Tampoco se cita al Consejo Superior de Investigaciones Científicas. El desarrollar diecisiete leyes autonómicas -sobre investigación y docencia universitaria- que se ignoren unas a otras sería una muestra de falta de madurez de la Universidad en España.

La LUC reconoce que la investigación universitaria se realiza en tres tipos de instituciones: grupos de investigación, departamentos, y centros de investigación. Sin embargo, no aprovecha la ocasión para institucionalizar los grupos de investigación con personalidad jurídica propia. Es un momento inmejorable para haber definido mejor esos grupos, su organización, y responsabilidades, e incluso haber innovado con imaginación. Es pues una ocasión perdida de haber impulsado realmente la investigación, sin el control de la jerarquía académica ya establecida. Se definen los "centros de investigación" aunque sin decir nada nuevo. Igualmente se definen los "institutos universitarios de investigación” sin añadir sustancia a la legislación estatal. El control de estos institutos se establece desde el Gobierno de la Generalitat, reduciendo la autonomía universitaria. Las universidades pueden crear parques científico-tecnológicos. Pero nada se dice de recursos de investigación, ni siquiera de bibliotecas que es uno de los puntos más problemáticos del sector universitario en la Comunidad Autónoma. Sólo se establece que la coordinación de esos recursos (biblioteca, cálculo, información, y comunicación) así como la transferencia de tecnología y conocimientos se realiza desde la Generalitat.

El artículo 83 de la LOU no desarrolla la realización por parte de la Universidad de contratos con el sector privado. Únicamente señala que "la universidad ha de ser compensada por todos los costos, directos e indirectos, que sean atribuibles a cada 
contrato". Pero no se especifica el uso posterior de ese dinero. De forma vaga se impulsa la creación de empresas o iniciativas innovadoras como parte de la capacidad emprendedora del personal de las universidades. Pero insiste en que ese proceso de creación de empresas "se han de preservar los intereses y los derechos económicos de la universidad". Se pierde aquí la oportunidad de desarrollar ese artículo 83, con innovaciones y una organización más explícita y progresiva.

La LUC también pierde la oportunidad de desarrollar la legislación de la LOU en lo relativo a grupo de investigación, y a la capacidad contratadora del personal (artículo 83 de la LOU). En esos dos extremos la Comunidad Autónoma catalana podría haber sido innovadora, y marcar la pauta del cambio al resto de las Comunidades Autónomas. Resalta la investigación como elemento esencial de la Universidad, pero eso ya está en la LOU. No se ofrece una organización progresiva, ni elementos de desarrollo. Este apartado era uno de los más esperados para medir la originalidad y progresismo de la ley autonómica, que desgraciadamente no supone originalidad. Solamente muestra repetidamente un entusiasmo europeísta respecto del Proceso de Bolonia, dentro de una típica pauta de misplaced concreteness.

\section{Excursus sobre Europa}

El actual europeismo sobre la Universidad debe ser analizado críticamente. La ley universitaria autonómica muestra un entusiasmo europeísta extraño, pues toma iniciativas sobre acuerdos y tratados que son discutidos y firmados por el Gobierno español. Se refieren a la reunión de Bolonia en junio de 1999, la de Praga en mayo de 2001, y la reunión de Berlín en septiembre de 2003. Todos esos acuerdos son firmados por España; y al menos inicialmente es el Ministerio de Educación el encargado de llevarlos a cabo en todo el territorio español. No es adecuada aquí la iniciativa $-y$ mucho menos el "protagonismo"- de una Comunidad Autónoma concreta. Las referencias al European Area of Higher Education, y a los cambios que se proponen para el año 2010, son innecesarios en una ley autonómica. Lo lógico hubiese sido referirse genéricamente a ellos para mostrar la conformidad obligatoria que suponen los tratados internacionales firmados por España. La ANECA es la agencia que acredita las titulaciones. Es además el Gobierno central quien debe marcar los cambios generales, y los plazos, todo ello coordinado para España. No se puede basar en iniciativas voluntaristas de cualquier Comunidad Autónoma.

Los cuarenta países del Proceso de Bolonia proponen una convergencia de sus múltiples sistemas universitarios -todos diferentes- hacia un modelo que es una copia del sistema estadounidense (sin mencionarlo nunca). La elite universitaria europea ha sido educada en Estados Unidos por lo que no debe extrañar esa influencia. El entusiasmo europeísta se observa en las medidas de convergencia que propone cambios cosméticos: un sistema de dos ciclos (báchelor y máster/doctorado), la apostilla en inglés a los títulos académicos, y la organización de la enseñanza en créditos europeos (ECTS) con sesenta créditos cada curso académico. Pero esta convergencia meramente formal es una cortina de humo para esconder el verdadero problema de la Universidad europea: su creciente falta de competitividad. Hasta hace unas décadas los países del mundo (incluyendo Estados Unidos) copiaban el modelo de la Universidad británica y alemana. Actualmente es al revés. España no se decide sobre si copiar a Centroeuropa o a Estados Unidos.

Los problemas reales de la Universidad europea -y en concreto de la española - no se van a arreglar con meros cambios formales o de organización. La decadencia es más profunda. Existen diez problemas principales: (a) Europa se ha estancado en un modelo de universidad elitista que apenas forma a la mitad de la juventud, mientras que en otros países avanzados del mundo se imparte educación postsecundaria a más del $85 \%$ de la población. En Europa se mantiene un modelo reproductor de clases medias y altas, que excluye a las clases bajas de la oportunidad de la educación postsecundaria. La consecuencia es que la población activa está poco preparada a nivel postsecundario ${ }^{14}$. (b) Europa posee mucho personal de investigación, pero investiga poco, y su productividad es baja, avanzando el conocimiento menos de lo esperable. Eso se traduce en una tasa de patentes baja (la mitad que Estados Unidos). No sólo la docencia, sino también la investigación y el avance tecnológico están en decadencia. (c) Europa ya no atrae tantos estudiantes extranjeros; cada vez menos de África, Asia y Latinoamérica. En Estados Unidos un tercio de la producción de doctores es de extranjeros, y en algunos campos (como ingeniería) alcanza el 50\%. (d) En el caso español, parte del problema es la escasez de recursos; España, por ejemplo, tiene un presupuesto de educación terciaria que es la mitad que la media de la OCDE. Las carencias de recursos de todo tipo (por ejemplo de bibliotecas) son enormes, y cada vez las diferencias con los países más desarrollados del mundo son mayores. (e) Además, en España las becas para estudiantes universitarios son muy reducidas tanto en proporción de estudiantes como en cuantía. Prácticamente no existe un sistema de préstamos. La población estudiantil es dependiente de sus padres, lo que crea problemas en la estructura social (como una tasa de natalidad bajísima). (f) Como consecuencias esperables, la tasa de abandono de la carrera, la de suspensos, y el alargamiento de la duración de la carrera son altas, produciendo que en algunos centros la mitad de estudiantes matriculados no terminen nunca la carrera. La tasa de fracasos correlaciona además con la clase social baja de los/as estudiantes que abandonan, contribuyendo a un modelo más elitista que el de acceso. (g) En España la situación del doctorado es peor aún, pues termina uno de cada cinco estudiantes que empiezan el programa de doctorado. Además los/as que obtienen el título de 
doctor luego apenas investigan. La situación es de abundancia de estudiantes, cierta plétora de doctores, pero una insuficiencia manifiesta de investigación. Las personas realizan un doctorado para conseguir un puesto de trabajo (docente) y no para investigar. (h) Falta una estratificación de universidades que suponga una especialización de funciones, así como una dedicación realista a la formación de docentes e investigadores. (i) Durante décadas la selección del profesorado ha sido endogámica, atendiendo a valores de amistad, lealtad, e incluso de lengua o tendencias ideológicas. Superar la estructura actual del personal docente va a requerir varias décadas más, si es que la nueva legislación -la LOU- logra superar el problema endogámico, antes de ser sustituida por una ley socialista. Algunas universidades locales están empeñadas en burlar la legislación, controlando el acceso de nuevos profesores y reforzando las barreras lingüísticas de algunas comunidades ${ }^{15}$. (j) La carencia más obvia a nivel comparativo con el mundo es la falta de personal no docente (lo que se llama PAS), que todavía no ha concentrado ningún interés en las políticas universitarias. (k) Ha habido progresos, como la extensión del número de estudiantes (pero cuya tasa actual está estancada) o el avance de la tasa de feminización del alumnado (que alcanza ya a 120 mujeres por cada cien varones). Pero la feminización no ha llegado a algunas áreas (como ingeniería), ni tampoco al profesorado (que son sólo 34\% mujeres). En los estratos de catedráticos, cargos académicos, y poder universitario la dominación masculina es prevalente.

La euforia europeísta -fuera del contexto institucional- no sirve para ocultar la insolidaridad con las otras dieciséis Comunidades Autónomas. Era previsible, pero negativo, que la primera ley universitaria autonómica que se aprueba en España (la LUC) fuese un caso de falta de colaboración con el resto de España.

\section{Capital humano}

En la LUC la Universidad se considera un sistema y también una comunidad. La "comunidad universitaria de Cataluña" es otra de las expresiones utilizadas por la LUC que incluye el capital humano de las universidades privadas y públicas; los cuatro grupos de estudiantes, personal docente, investigador, y PAS. Entre los objetivos de la Generalitat está "la plena consolidación de la comunidad universitaria de Cataluña como parte integrante de la comunidad universitaria europea y de la comunidad científica internacional, estableciendo vínculos de colaboración académica e interuniversitaria e implementando flujos de movilidad entre los miembros de estas comunidades" (artículo 30.b). No hay una referencia a la integración con las otras dieciséis
Comunidades Autónomas, o con la comunidad universitaria española.

Sobre estudiantes no innova nada. Más bien se adopta una actitud regresiva al señalar que las pruebas de acceso a la universidad (las antiguas PAAU) se hagan conjuntamente para todas las universidades, en vez de avanzar en la autonomía de cada universidad, que supuso un avance de la LOU. La LUC se excusa señalando que así los/as estudiantes concurren a los procesos de acceso "en igualdad de oportunidades". La legislación de la administración central había dado un paso adelante descentralizando los sistemas de acceso, para que luego el Gobierno de la Comunidad Autónoma los vuelva a centralizar.

Se señala que el Gobierno de la Generalitat debe adoptar medidas para que "los/as estudiantes que hayan accedido a las universidades de Cataluña puedan continuar sus estudios en otras universidades de Europa”. ¿ ¿Por qué no en España, o en el mundo? De nuevo, este falso europeismo trata de ocultar una actitud poco solidaria con el resto de España. Esta sección sobre estudiantes (artículos 32 a 41) es quizás el espacio en que la ley debería haber señalado el objetivo de abrir el acceso de la Universidad al 50\% de población que normalmente no realiza estudios universitarios en esa Comunidad Autónoma. Era importante establecer objetivos y metas concretas de universalización. Pero la LUC prefiere no referirse a ese tema, y señalar sólo la movilidad hacia Europa de los estudiantes de clases medias y altas que son las que forman la población estudiantil universitaria actual. Entre los derechos de los/as estudiantes la ley señala el de "no ser discriminado por razones de nacimiento, género, orientación sexual, etnia, opinión, religión o cualquier otra circunstancia personal o social" (artículo 37.b). En esta lista clásica de derechos civiles habría que haber incluido explícitamente "la lengua".

Otro tema importante -en el que se esperaba una definición de la LUC- es la bajísima tasa de estudiantes con beca (u otras ayudas económicas, como préstamos). La LUC opta por la ambigüedad, con lo que no puede ser acusada de nada, y tampoco compromete recursos. Se refiere únicamente al artículo 45 de la LOU, repitiendo que se requiere "una política de créditos y becas que garanticen que ninguno que reúna las condiciones para cursar estudios universitarios con aprovechamiento, quede excluido por razones económicas" añadiendo además "que permita también adaptar el sistema general a las necesidades socioeconómicas y territoriales de Cataluña”. Es puro discurso, pues no concreta nada, ni planifica un sistema de becas apropiado. El problema es más grave en esta Comunidad Autónoma pues la discriminación de las clases bajas e inmigrantes es mayor. La falta de un sistema de becas y otras ayudas económicas a los/as estudiantes es uno de los puntos más criticados de la LOU, que la LUC tampoco desarrolla. La ley se expresa con ambigüedad, sin comprometer ningún tipo de recurso especial. Es otra de las ocasiones perdidas de promulgar una ley progresista e innovadora. El sistema universi- 
tario en Cataluña no va a progresar si no se regula un acceso mucho mayor de la población a la Universidad, y se complementa con un sistema de ayudas económicas a los/as estudiantes que sea real y expansionista. Se hubiese requerido un plan especial, con objetivos concretos. La LUC cae repetidamente en el problema de misplaced concreteness, legislando detalladamente las prerrogativas y el poder del Gobierno de la Generalitat, pero nunca sus responsabilidades concretas. El desequilibrio legislativo es evidente, y puede tener consecuencias negativas para la población. Por lo que respecta al resto del articulado sobre estudiantes en la LUC no hay nada original ni innovador.

La ley pone un énfasis especial en la creación de escalas nuevas de profesores contratados, prometiendo además que se van a dotar al menos cien profesores nuevos permanentes ("catedráticos" y "agregados") cada año, durante los próximos doce años. Esta cantidad, que además se consigue en parte con las jubilaciones de profesores, no es muy alta; apenas representa un 7,5\% del total del profesorado universitario. ${ }^{16}$ En el año 2000 España tiene -según los datos oficiales más actuales- cerca de cien mil profesores universitarios (exactamente 99.619). En Cataluña hay 16.043 profesores, es decir, aproximadamente el 16\% del total. La situación de profesorado en Cataluña es buena, bastante mejor que la media española. Se puede afirmar que el profesorado es el menor de los problemas de las universidades catalanas. En relación con la población estudiantil universitaria la tasa de profesorado en la Comunidad Autónoma catalana es un 28\% mejor que la media española, un 3\% mejor que la Comunidad de Madrid, e incluso un 43\% mejor que en el País Vasco. Sin embargo, la LUC propone una expansión relativa del profesorado con la creación de 1.200 nuevos profesores permanentes ("agregados" y "catedráticos") que se llevaría a cabo en el plazo de doce años ${ }^{17}$. Por Ley Orgánica (LOU 2001) el profesorado funcionario debe ser al menos un $50 \%$ del total, con lo que el profesorado contratado de Cataluña debería ser -según los datos oficiales- 8.021 profesores contratados. Los 1.200 profesores permanentes que se ofrecen en la ley (en las disposiciones finales) supondrían el 15\% del total. Dicho de otra forma, en la mitad del profesorado que es profesorado contratado un 15\% sería permanente y el $85 \%$ restante temporal. Las 400 plazas de catedráticos (contratados permanentes) que se crean en esos doce años, al día de hoy supondrían un 5\% del total de contratados. Se propone pues un modelo que es el doble de jerárquico que el actual funcionario. La propuesta no parece la más apropiada, pues exagera los problemas que ya tienen las universidades creando un sistema alternativo excesivamente piramidal y jerárquico. Además, con un $15 \%$ del profesorado contratado (7,5\% del profesorado total) no se transforma la estructura general del personal académico. La ley resulta pues insuficiente, lenta e imperfecta.

La situación actual de la tasa de profesores universitarios en Cataluña es buena, y no requiere expansión. Las universidades de la Comunidad Autónoma tienen 7,7 profesores por cada cien estudiantes, es decir, una tasa que es un $28 \%$ más alta que la media española y no inferior a otros países como Estados Unidos. El problema de las universidades españolas (incluyendo Cataluña) es la falta manifiesta de PAS. La ley debería haber resuelto ese problema, y no haber dedicado tanta atención al profesorado, y a la creación de numerosos tipos de profesorado. Al final hay 14 tipos de profesores, 4 tipos de investigadores, y varios tipos de becarios entre ellos en formación investigadora (y parcialmente docente). Es una estructura confusa y laberíntica. A nivel comparativo la Comunidad Autónoma tiene una tasa de PAS que es un $28 \%$ más alta que la media de España. Pero el PAS sólo alcanza a ser el $42 \%$ de la tasa de profesorado, lo que a nivel internacional es insuficiente. Llama pues la atención que la ley dedique tanta atención a un sector que no es problemático (profesorado) olvidando totalmente otro que sí lo es (PAS). La explicación está en el poder que otorga establecer una pirámide propia de profesorado - controlada por la Comunidad Autónomaparalela, y supuestamente al mismo nivel salarial que la pirámide de profesorado funcionario. Permite, por ejemplo, conceder plaza de "catedrático" o de "agregado" (equivalente a titular) a personas que no logran ganar la habilitación en el concurso a nivel de toda España. Supone una puerta trasera que en ocasiones puede permitir recompensar otro tipo de fidelidades. Por eso era tan importante que permitiese niveles altos de profesorado, hasta "catedrático", pues esa es la verdadera recompensa. Parece más una medida clientelista, y de poder de la Generalitat, que un recurso racional necesario para las universidades catalanas.

El profesorado de las universidades se estructura en categorías distintas. A nivel nacional (español) hay cuatro cuerpos de profesores funcionarios. A ellos se añade una estructura de once tipos adicionales de profesorado contratado. La innovación es que los profesores contratados en vez de ingresar por los niveles más bajos de la pirámide docente, pueden hacerlo también por arriba, a un nivel equiparable a los cuerpos de funcionarios. Se consigue así un modelo de dos sistemas estratificados -dos pirámides paralelas- de profesores:

\begin{tabular}{|c|}
\hline Pirámide de funcionarios: \\
1. Catedrático de universidad \\
2. Profesor titular de universidad \\
3. Catedrático de escuela universitaria \\
4. Profesor titular de escuela universitaria \\
Pirámide de contratados: \\
5. Catedrático \\
6. Profesor agregado \\
7. Profesor colaborador permanente \\
8. Profesor lector \\
9. Profesor colaborador temporal \\
10. Profesor asociado \\
11. Profesor visitante \\
12. Profesor emérito \\
13. Profesor honorario \\
14. Ayudante
\end{tabular}


Los tipos 3 y 4 son casi a extinguir, dado que ya sólo se convocan plazas nuevas en el 6\% de las 187 áreas de conocimiento; y las Escuelas Universitarias pueden casi desaparecer en el futuro. Los tipos 5 y 6 son contratos permanentes, y supuestamente equiparables en salarios y algunos derechos a los tipos 1 y 2. La ley asegura explícitamente (artículo 43.2) la identidad de derechos entre catedrático-funcionario/catedrático-contratado y entre titular/agregado. Esto no es posible enteramente, pues los contratados no pueden pertenecer a las Comisiones de habilitación, y con limitaciones a las de acceso. Tampoco pueden tener derecho a las retribuciones conocidas como "tramos" o "sexenios" de investigación. Es decir, que la Comunidad Autónoma organiza una pirámide alternativa de profesorado, que incluye -por vez primera- personal contratado permanente a nivel alto. Ésta es seguramente la mayor innovación de toda la ley. El profesorado con ambiciones de lograr un puesto alto en el escalafón, pero con dudas de poderlo conseguir en una competición a nivel de toda España, apoyan decididamente esta parte de la ley.

Los tipos de profesorado son numerosos, y excesivos en número: catorce tipos de profesores. Complican mucho la estructura docente de las universidades. No es factible organizar una universidad que tiene catorce tipos distintos de profesores, además de becarios y cuatro tipos de investigadores que pueden también realizar alguna labor de docencia. Además, los salarios dentro de cada tipo pueden ser variables ya que la ley admite la posibilidades de complementos de categoría, y de gratificaciones excepcionales (artículo 71). Se construye así un sistema jerárquico extraordinariamente complicado y casuístico, con la nota dominante de que no es un sistema de estratificación, sino dos o tres sistemas paralelos que coexisten: cuatro cuerpos de funcionarios, tres tipos de profesorado permanente, y siete tipos de profesorado temporal. La LOU asegura que el primer grupo (y pirámide) debe ser al menos el 50\% del profesorado total. Es el Ministerio de Educación (MEC) quien controla que la norma del $50 \%$ se cumple. Pero el problema no son los catorce tipos, sino que la estructura del profesorado es jerárquica y piramidal.

Los concursos de profesorado contratado (temporal y permanente) se hacen públicos en el DOGC y también se comunican al Consejo de Coordinación Universitaria. Se define catedrático como "una carrera docente e investigadora consolidada" y agregado con "una probada capacidad docente e investigadora”. En ambos casos se requiere tres años de investigación postdoctoral, tal y como señala precisamente la LOU. Para agregados se requiere una "acreditación de investigación" realizada por la Agencia para la Calidad de la Comunidad Autónoma, y para catedrático se pide una "acreditación de investigación avanzada”. Estos títulos o expresiones no explican lo que realmente se demanda, ni cómo se va a evaluar. Habrá pues que esperar a la práctica. Se pide además un informe de la actividad docente.
Un detalle innovador es que se trata de evitar la endogamia mediante el requisito de que la persona candidata al puesto debe certificar dos años de actividad docente o investigadora fuera de la universidad que convoca la plaza. La especificación es: "acreditar dos años de actividad docente o investigadora, predoctoral o postdoctoral, o de transferencia de tecnología o de conocimientos, en situación de desvinculación académica de la universidad convocante. Este requisito se considera cumplido si los estudios de doctorado han estado integramente cursados, y el titulo de doctor expedido, por una universidad diferente de la convocada" (artículo 47c). Este artículo es innovador-seguramente el más interesante de la LUC- pues supone que el profesorado se doctora en una universidad pero debe buscar trabajo en otra universidad. Como en la Comunidad Autónoma hay once universidades (siete públicas, dos semipúblicas, y dos privadas) el sistema es posible. Sería más difícil o impracticable en Comunidades Autónomas con pocas universidades. Esta norma va a producir muchas quejas entre el profesorado actual con ambiciones de conseguir un puesto permanente. Para evitar otra "rebelión de penenes" la propia ley incluye al final una disposición transitoria (la séptima) haciendo inválida esta norma en muchos casos: cuando en diciembre de 2001 ya eran ayudantes o profesores asociados en su universidad, o incluso si ya eran funcionarios (de cualquiera de los cuatro cuerpos de funcionarios). Es poco útil que se promulgue una norma antiendogámica para luego presentar como excepciones precisamente los casos que ambicionan esa endogamia. Pero si esta ley y norma permanece (sospechamos que se intentará sortear con normativas sucesivas) se puede convertir en una de las mejores innovaciones de la LUC. Por vez primera el profesorado debe contrastar su conocimiento y preparación en universidades distintas en vez de seguir el consejo tradicional de calentar la silla. Sería útil para otras Comunidades Autónomas (fundamentalmente la Comunidad de Madrid que tiene varias universidades) copiar este requisito.

La contratación de profesorado sigue a la LOU (en sus artículos 51 y 52). Así, establece la figura del profesor colaborador para unas áreas específicas del conocimiento donde supuestamente las necesidades son más perentorias. La LUC innova al establecer que esos profesores colaboradores pueden ser permanentes, lo que en realidad no está en el espíritu de la ley. Necesitan un informe favorable de la Agencia para la Calidad (autonómica); pero sorprendentemente este informe es de carácter indefinido. No se entiende que un informe que acredite el nivel docente/investigador pueda tener carácter indefinido; más bien debería ser lo contrario.

Otra invención es la figura del profesor lector como un profesor ayudante pero que es doctor. Es el paso inicial en una carrera docente, y es temporal por sólo cuatro años. Requiere la misma cláusula de desvinculación con la universidad de al menos dos años, o que el doctorado sea de otra universidad. Esta vez se 
especifica "que, al menos durante dos años, no ha tenido relación contractual, estatutaria o becaria con la universidad correspondiente, o bien que los estudios de doctorado han estado integramente cursados, y el titulo de doctor expedido, por otra universidad". La regla de los dos años se aplica pues al itinerario normal de carrera académica; profesor lector cuatro años, luego profesor agregado, y por fin catedrático. Pero no se requiere para otros tipos de contrato más precarios, como profesor colaborador temporal o permanente, profesor asociado, y ayudante. Para continuar con la endogamia, y evitar la norma de los dos años, basta con pasar de becario de FPI durante cuatro años, a ayudante otros cuatro años, y posteriormente a profesor colaborador permanente. Otro sistema es realizar la habilitación/acceso y convertirse en funcionario. Dado que los contratos de agregado y catedrático no van a representar más que un 7,5\% del total de profesorado -y eso en el año 2015- la regla de los dos años es más simbólica que real para la estructura general del profesorado. En cualquier caso yo considero que es positiva.

La ley repite varias veces que no habrá diferencias entre el personal contratado-permanente y el funcionario. Sin embargo, reconoce que un/a funcionario jubilado (incluso si lo es de otra universidad) puede pasar a ser profesor emérito, es decir, contratado y retribuido. Se requiere que "hayan prestado servicios destacados a la universidad" (¿en cuál?). Sin embargo, el profesorado contratado sólo puede convertirse en profesor honorario, que por su propio nombre no supone retribución económica. El año sabático de los profesores contratados permanentes requiere una adscripción a una universidad de fuera de Cataluña.

La ley es un poco confusa en lo relativo al tipo de investigadores que se crean. Parece ser que hay cuatro tipos, todos ellos con el título de doctor.

\section{Cuatro tipos de investigadores: \\ 1. Investigador \\ 2. Investigador posdoctoral \\ 3. Investigador vinculado \\ 4. Investigador contratado por obra o servicio}

Los dos primeros tipos $(1,2)$ deben tener al menos dos años de antigüedad como doctores, y proceder de una universidad diferente. Son contratados por cinco años. El cuarto tipo (4) es contratado para un proyecto concreto. Existen además los investigadores en formación, que son todos los/as estudiantes de doctorado. Incluye becarios, becarios de investigación, y ayudantes. El ayudante es un figura parcialmente investigadora y docente. Debe ser un/a estudiante de doctorado que haya superado todas las materias de estudio propias del título de doctor; sin haber transcurrido más de cuatro años. La ley especifica que puede "colaborar en tareas docentes". Es contratado por un máximo de cuatro años. Así pues, mientras no se sea doctor se puede ser docente en la propia universidad sin que se aplique la regla de los dos años de desvinculación.

En esa sección, la ley reconoce explícitamente que la docencia de doctorado se considera como "cumplimiento de las obligaciones docentes". Es un paso para reconocer el doctorado como trabajo normal de un profesor, superando la situación actual de que no cuenta como parte del trabajo o sólo de forma reducida. Es el único avance en el tema de doctorado, aspecto que la LUC apenas regula.

Las universidades no tienen autonomía para fijar las retribuciones del profesorado y personal investigador. Las retribuciones del personal académico contratado son establecidas por el Gobierno de la Generalitat; y son iguales para las universidades públicas. Es otro ejemplo de la falta de autonomía de las universidades. Se admite únicamente la posibilidad de gratificaciones o indemnizaciones excepcionales "por razón del servicio". Se establece además retribuciones adicionales por méritos docentes, investigadores o de gestión, que deben ser evaluadas por la Agencia para la Calidad ${ }^{18}$.

El personal de administración y servicios (PAS) ocupa cuatro artículos en la LUC (73 a 76) que no incluyen ningún aspecto innovador. Nada se dice de la necesidad de un incremento considerable de la tasa de PAS. Tampoco se debate el incremento del salario para conseguir sueldos dignos. Siendo uno de los problemas estructurales más importantes de la Universidad, sorprende que no se dediquen más esfuerzos a mejorar la estructura actual. La LUC da prioridad al profesorado: se crean nuevas figuras de profesores pero no de PAS.

\section{Estructura de las universidades públicas}

En cuanto a la estructura de las universidades (públicas) la LUC parte fundamentalmente de la LOU, siendo original solamente al definir el Consejo Social de las universidades, y al crear una asociación de antiguos alumnos/as. Advierte que en los procesos electorales hay que dar una importancia especial al profesorado contratado permanente doctor, con "una representación significativamente destacada"; se entiende que por encima de otro tipo de personal no funcionario.

Sobre la figura del rector (o rectora) y del gerente (o gerenta) la LUC no dice nada que no esté ya en la LOU, dejando claro que el nombramiento oficial del rector o rectora corresponde al Gobierno de la Generalitat. 
El Consejo Social -su nombramiento y funciones- aparece detallado en los artículos 81 a 98 siendo uno de los apartados novedosos. El artículo 14.3 de la LOU establece que la Ley de la Comunidad Autónoma es la que debe regular la composición y funciones del Consejo Social, advirtiendo que seis miembros de la Universidad (rector, secretario general, gerente, un profesor, un estudiante, y un PAS) deben formar parte del Consejo Social. La LOU señala también que el Presidente es nombrado por la Comunidad Autónoma. La LUC detalla -cómo es esperable- la composición del resto de los miembros del Consejo Social. Ésta era una prueba del nivel democratizador y autonómico de la LUC. El resultado es que el modelo elegido es estatalizado y poco favorecedor de la autonomía de las universidades.

El Consejo Social de cada universidad está compuesto por quince miembros. Seis son los que establece la LOU, elegidos como está previsto entre los miembros del Consejo de Gobierno de la universidad. Los otros nueve miembros son: dos personas nombradas por el Gobierno de la Generalitat; tres por el Parlamento catalán; un antiguo alumno; una persona elegida por los entes locales territoriales (en el caso de Barcelona, por ejemplo, por el Ayuntamiento de Barcelona); una por las organizaciones sindicales; y la última por las organizaciones empresariales. El Presidente es elegido directamente por el Gobierno de la Generalitat entre estos nueve miembros. A su vez el antiguo alumno/a es nombrado por el Presidente (oído el rector o a propuesta del consejo de antiguos alumnos); es decir el miembro que debería ser más independiente es nombrado por el Gobierno. Seis miembros de estos nueve -incluyendo al Presidente- son elegidos por el Gobierno autonómico. Eso supone que de los 15 miembros nada menos que el 40\% son elegidos por el Gobierno, contando además con la presidencia. El Consejo Social no puede considerarse como un organismo independiente, ni externo.

Hay artículos cabalísticos, típicos de los círculos viciosos de poder que proliferan a nivel local. Es el caso del artículo 82.3 en que se señala que los tres miembros del Consejo Social nombrados por el Gobierno de la Generalitat, lo son "previa consulta al presidente del consejo social, siempre que el cargo no esté vacante". ¡Pero si el Presidente ha sido a su vez nombrado por el Gobierno de la Generalitat! Es absurdo que cargos nombrados por el mismo Gobierno se supone que tienen que solicitar una consulta previa. ¿Para qué? Quizás la LUC trata de dar una cierta sensación de democracia, cuando en el fondo se establece un Consejo Social controlado por el Gobierno autonómico, y que deja poca autonomía a la universidad. Con esta organización no se puede afirmar que el Consejo Social suponga la participación de la sociedad en la universidad. La ambigüedad es máxima cuando la LUC disculpa está realidad con la posibilidad de organizar un "Foro de Participación" para promover la participación y asesoramiento de las instituciones sociales. Como no se regula la estructura, ni los objetivos, ni funciones, ni el poder de ese Foro, la medida está llamada a no tener significado real. La existencia de ese Foro de Participación no vuelve aparecer posteriormente en la ley.

El poder de la Generalitat es patente al especificar las funciones del Consejo Social con detalle. La LUC dedica un espacio considerable a definir siete funciones de programación y gestión, doce funciones económicas, y once funciones adicionales. En total pues hay 30 funciones detalladas. Supera el espíritu de la LOU, que prevé para el Consejo Social un papel de control de presupuestos, y sobre todo la de conseguir dinero y recursos para su universidad. La LUC da la vuelta a esa organización proponiendo un Consejo Social controlador de casi todos los aspectos organizativos y de gestión de la universidad. No se van a detallar aquí las 30 funciones (véanse los artículos 88, 89 y 90 de la ley), pero sí comentar algunos de los excesos de control que se proponen. Por ejemplo, el Consejo Social no sólo controla la planificación estratégica de la universidad, sino todos los centros y enseñanzas, incluyendo los institutos universitarios, e incluso la evaluación de la calidad. No sólo aprueba los presupuestos, sino que realiza un seguimiento del presupuesto, con todas las transferencias de crédito, estableciendo los precios de las enseñanzas y servicios dentro de la universidad. Asigna además retribuciones adicionales al personal de la universidad, de forma singular e individual. Establece la relación de puestos de trabajo del PAS, así como los complementos de productividad e incluso las gratificaciones. Controla el nombramiento del gerente y sus condiciones. Acuerda la política de becas; también las normas de permanencia. La lista de funciones y controles es larga. Incluso se supone que debe "velar por la correcta inserción laboral de los titulados de la universidad" (sic). El Consejo Social deja poca autonomía al rector o a la universidad.

No queda claro cómo va a realizar el Consejo Social tanta actividad y desarrollar estas funciones. Nunca se señala si los miembros tienen un salario, pero la enumeración de funciones es $\tan$ extensa, que requiere un trabajo diario, de varias horas y dedicación. El Consejo Social se organiza en Comisiones, lo que supone más influencia para el grupo central de poder dentro del organismo, que es el elegido por el Gobierno de la Generalitat. Se establece un presupuesto propio para el Consejo Social, dentro del presupuesto de la universidad, aunque en realidad es un organismo fundamentalmente dependiente del Gobierno de la Generalitat. La organización es impráctica, y controladora por parte del Gobierno. No puede hablarse de autonomía universitaria en Cataluña con unos Consejos Sociales diseñados de esta forma.

Otra innovación menor de la LUC es el Consejo de Antiguo Alumnado y de Personas Amigas de la Universidad (CAAPAU). Es una innovación menor pues su poder se resume en un miembro en el Consejo Social, que es además nombrado por el Presidente del Consejo Social (quien previamente ha sido nom- 
brado por el Gobierno de la Generalitat). No queda claro cómo se va a organizar la figura de "amigo de la universidad". Las funciones de este consejo son igualmente ambiguas.

La organización de las universidades públicas supone el establecimiento de un Consejo Social con poder, muchas funciones, y que depende fundamentalmente del Gobierno de la Generalitat. No es un organismo externo que ayuda a conseguir recursos económicos para la universidad, ni tampoco una forma de articular la participación de la sociedad. Es sobre todo un sistema de poder de la Generalitat sobre las universidades, que ven -según la LUC- muy disminuida su autonomía universitaria. Se ha elegido el peor modelo: poco democrático, nada externo, y bastante estatalizado. A pesar de que el Gobierno nombra directamente al $40 \%$ de los miembros del Consejo Social, éste ni siquiera tiene el poder de nombrar a su presidente, sino que es nombrado por el Gobierno de la Generalitat, a propuesta del Consejero de Universidad respectivo (otro de los múltiples "círculos viciosos del poder local" típicos de estructuras pseudodemocráticas). Si se pretenden universidades con autonomía no se pueden diseñar Consejos Sociales con tanto poder, dependientes directamente del Gobierno de la Comunidad Autónoma.

\section{Gobierno autonómico y las universidades}

A partir del artículo 101 -y hasta el final- la LUC dedica la mayor parte del texto legal a las funciones y el poder específico del Gobierno de la Generalitat en el sector universitario. Utiliza la expresión "departamento competente en materia de universidades" (que podemos abreviar como DCMU) para no tenerlo que citar por el nombre en uso -Departamento de Universidades, Investigación y Sociedad de la Información DURSI- dado que previsiblemente su nombre puede cambiar. Se entiende que las decisiones se toman por el Consejero respectivo (Conseller) que es parte del Gobierno de la Generalitat. Se está hablando pues de un poder directo del Gobierno de la Comunidad Autónoma en el sector universitario.

El apartado de régimen jurídico de las universidades no ofrece novedad. La creación y reconocimiento de las universidades se amolda a lo que dice el artículo 4 de la LOU. La LUC mantiene un cierto aire de independencia en la creación de universidades, pero es la LOU la que establece el procedimiento, siendo preceptivo el informe previo del Consejo de Coordinación Universitaria. La LUC añade además otro informe de la Junta del Consejo Interuniversitario de Cataluña a pesar de que actualmente el $54 \%$ de sus miembros son nombrados por la Generalitat, además de la Presidencia. No es pues un informe que cree ningún problema a la Generalitat, pues se trata de un informe del Gobierno al Gobierno (otro de los "círculos viciosos" de la LUC). El Gobierno de la Generalitat aprueba además los estatutos de las universidades públicas y los correlativos de las universidades privadas.

La Consejería de Universidad -sea cual sea el nombre que esté en vigor- canaliza el poder de la Generalitat en el resto de asuntos con las universidades: creación, modificación, integración y supresión tanto de centros como de enseñanzas. Controla los planes de estudio (los informa a petición del rector); también la ubicación (y denominación) de los centros docentes. Controla los centros extranjeros que imparten docencia en Cataluña. Una novedad de la ley es la posibilidad de crear campus interuniversitarios, ya sean presenciales o virtuales, compartiendo recursos humanos y de otro tipo. Este artículo 11.2 parece escrito para hacer posible la existencia de la UOC.

\section{Planificación}

Lo que en el argot de la burocracia española se denomina "ordenación", en la LUC se realiza a través de una programación plurianual, con un sistema de financiación múltiple, que incluye un plan de inversiones de varios años. No hay grandes novedades en esta formulación que cristaliza lo que ya se está realizando antes de la LUC. La programación incluye a las universidades públicas, pero también a las privadas "que soliciten ser incluidas". El Gobierno define lo que entiende por "equilibrio territorial" de universidades y enseñanzas. Aquí la LUC, tímidamente, incluye un cambio relevante, pues explícitamente establece "la especialización y diversificación universitaria en un contexto de cooperación interuniversitaria"; se entiende de las once universidades de la Comunidad Autónoma. Estas dos líneas del artículo 116.c dejan una puerta abierta para la diferenciación de universidades, algo que el sector universitario catalán, y el del resto de España, no había formulado hasta ahora.

Los precios públicos de la enseñanza son aprobados por el Gobierno de la Generalitat. Esa es la piedra angular de la financiación. Lo novedoso (aunque ya se está realizando) es que las universidades reciben una financiación básica ("genérica" se denomina en la ley), pero el resto proviene del llamado contrato-programa. Ésta es una financiación que depende de unos objetivos específicos (supuestamente para la mejora de la calidad de las universidades) que se valoran con unos indicadores previstos por el Gobierno autonómico, y que a su vez se relacionan con los objetivos. Otra financiación adicional proviene de convocatorias públicas para estimular supuestamente la mejora de la calidad y premiar la excelencia. Pero en ningún sitio se explica cómo se mide esa calidad o esa excelencia. Se supone que es el Gobierno de la Generalitat quien la define, no un organismo externo. El 
sistema de financiación reduce la autonomía de las universidades catalanas.

\section{Coordinación}

Copiando el Consejo de Coordinación Universitaria para toda España, la LUC establece un organismo paralelo para la Comunidad Autónoma que denomina "Consejo Interuniversitario de Cataluña" (CIC). A este nuevo organismo le dedica atención (artículos 121 a 136 de la ley). El papel del CIC no es de gestión ni tampoco decisor, sino múltiple de coordinación, consulta y asesoramiento del Gobierno de la Generalitat. Pero la ambigüedad de esta creación es que el CIC es mayoritariamente un organismo cuyos miembros son nombrados por el propio Gobierno de la Generalitat. Es curioso pues que sea el Gobierno el que nombre un organismo para que luego "le aconseje”. Es otro círculo vicioso de poder a nivel autonómico.

A esta altura de la LUC es posible establecer una serie de hipótesis sobre la distribución del poder universitario en la Comunidad Autónoma: (1) La LUC crea diversos organismos. Ya vimos el Consejo Social de las universidades (en que el 40\% de los miembros son nombrados por el Gobierno). Pero crea también el CIC, y posteriormente veremos la Agencia para la Calidad. Son todas ellas instituciones gubernamentales, en donde la Presidencia es siempre nombrada directamente por el Gobierno. En el fondo son organizaciones que se controlan unas a otras, dependiendo todas del mismo poder. Ninguna de ellas es independiente, y mucho menos externa. Esta estructura de organizaciones múltiples con fronteras borrosas supone un sistema de funcionamiento pseudodemocrático, pero que en el fondo difumina la responsabilidad, conservando el control último en el Gobierno de la Generalitat. (2) Cada una de estas organizaciones tiene una larga lista de funciones, mucho más extensas de lo esperable. Son controladoras de la Universidad. Eso supone dos cosas: poca autonomía de las universidades concretas, y poca confianza en la capacidad equilibradora del mercado. El Gobierno no se dedica a financiar y coordinar la Universidad, sino que realmente, dirige, controla, e incluso gestiona, hasta aspectos menores. Es posible que este modelo de control lleve a veces a un caos administrativo. (3) Aquí se podría aplicar el proverbio de que too many cooks spoil de broth: no son necesarios tantos organismos, controlándose unos a otros, sobre todo si a su vez dependen del mismo Gobierno y ninguno es externo. Puede llevar a situaciones de "es mejor no hacer nada", a veto points, y a situaciones de conflictos de celos entre personalidades nombradas a dedo por el propio Gobierno. (4) El modelo es excesiva- mente reglamentista (no era necesario serlo). El Departamento respectivo -el de Universidad- tiene según la LUC una larga serie de atribuciones y controles. Esto disminuye en la práctica la pequeña autonomía de cada universidad, sobre todo en el caso de las universidades públicas. (5) El sistema es centralista pues las presidencias de todas las organizaciones autonómicas son nombradas por la Generalitat. En el caso del CIC la presidencia de los organismos internos y comisiones recaen además en el Consejero de Universidad. (6) Nunca queda establecido quién evalúa a estos organismos, o ante quién son responsables. En plena cultura de la calidad, la excelencia, y la evaluación, la LUC no establece cómo se evalúan los órganos que dirigen y coordinan el sector universitario en esa Comunidad Autónoma. (7) El crear comisiones del Gobierno asesorando al propio Gobierno supone una dinámica de falta de responsabilidad política. Las decisiones son tomadas políticamente, pero se deciden de forma colegiada. Los/as rectores tienen que resignarse a la falta de protagonismo, y al mismo tiempo ser compañeros de viaje de todas las decisiones que se tomen sobre las universidades que dirigen. (8) El aparato político que se crea por encima de las universidades es desproporcionadamente grande y poderoso. No se requiere tanta burocracia para once universidades, algunas de ellas muy pequeñas (Internacional, Vic, Pompeu, Lleida). Estas ocho hipótesis dibujan un sistema de funcionamiento burocrático, conservador, con déficits democráticos, y fundamentalmente centralista.

Veamos los datos que sustentan estas hipótesis. El CIC funciona con un sistema presidencialista, cuyo presidente/a es el propio Consejero de Universidad como miembro del Gobierno de la Generalitat. Dentro del CIC hay tres organizaciones. La Conferencia General es un comité extenso y por lo tanto poco operativo (83 miembros en la actualidad) pero que se reúne solamente dos veces al año. Luego está el Pleno de la Junta que está compuesto de 24 miembros que incluye cuatro personas de universidades privadas. Para evitar que el sector privado pueda tomar decisiones sobre el sector público (algo que según las proporciones que estamos manejando es imposible) se configura una Junta Permanente muy parecida al Pleno de la Junta, compuesta por 21 miembros (veinte de ellos del sector público, más el rector de la UOC). Las universidades privadas no van a tomar decisiones en el CIC sobre las universidades públicas, porque en realidad tampoco las universidades públicas pueden tomar decisiones sobre ellas mismas. La proporción de miembros elegidos directamente por el Gobierno de la Generalitat es alta: son el $33 \%$ de la Conferencia General, 54\% del Pleno de la Junta, y $62 \%$ de la Junta Permanente. Se pueden comparar esos porcentajes con el resto de las organizaciones del sector universitario catalán en el siguiente cuadro.

El CIC es como un Consejo de Coordinación Universitaria, pero sólo para la Comunidad Autónoma, y sus once universidades, que es controlado fundamentalmente por el Gobierno. En ese sentido no es un organismo de coordinación de las propias 


\begin{tabular}{|c|c|c|c|c|}
\hline & $\begin{array}{c}\text { Número de } \\
\text { miembros }\end{array}$ & $\begin{array}{l}\text { Elegidos por } \\
\text { la Generalitat }\end{array}$ & $\%$ & $\begin{array}{l}\text { Presidencia } \\
\text { nombrada por } \\
\text { a Generalitat }\end{array}$ \\
\hline Consejo Social de la Universidad & 15 & 6 & $40 \%$ & Sí \\
\hline Consejo Interuniversitario de Cataluña & & & & Sí \\
\hline Conferencia General & 83 & 27 & $33 \%$ & Sí \\
\hline Pleno de la Junta & 24 & 13 & $54 \%$ & Sí \\
\hline Junta Permanente & 21 & 13 & $62 \%$ & Sí \\
\hline Agencia para la Calidad & & & & Sí \\
\hline Consejo de Dirección & 27 & 16 & $59 \%$ & Sí \\
\hline Comisión Evaluación Calidad & $\ldots$ & $\ldots$ & $100 \%$ & Sí \\
\hline Comisión Profesorado & 8 & 8 & $100 \%$ & Sí \\
\hline Comisión Evaluación Investigación & 21 & 21 & $100 \%$ & Sí \\
\hline
\end{tabular}

universidades, sino de control gubernamental. No se enumera aquí cada miembro del CIC, pues se puede consultar el artículo 127 para la Conferencia General, y el 129 para la Junta. El cálculo de los miembros totales y los/as elegidos por el Gobierno de la Generalitat se basa en la situación actual de once universidades (siete de ellas públicas). Puede variar ligeramente en el futuro, pero las proporciones serán similares. Se pueden formar además comisiones (permanentes y temporales) apenas definidas en la ley.

Dentro del CIC, la Conferencia General es supuestamente "el órgano de participación y de coordinación de la comunidad universitaria para conocer y evaluar los objetivos principales del sistema universitario". No es un organismo ejecutivo, sino que se limita a conocer y opinar sobre los objetivos propuestos por el Gobierno. Un tercio de los/as miembros son elegidos por el propio Gobierno, con lo que sus opiniones no van a suponer sorpresa. La LUC define comunidad universitaria como el conjunto de estudiantes, profesores, investigadores y PAS. Pero esta Conferencia General no es la representación de esos cuatro colectivos. Incluso si se tienen en cuenta exclusivamente los/as catedráticos, en la Conferencia General los/as rectores suponen solamente el 13\% de los miembros. No es una Junta de Rectores Catalanes. Además por cada rector está también el presidente del Consejo Social de su universidad que es nombrado, como ya se ha visto, por el Gobierno de la Generalitat. La Conferencia General tiene una lista detallada de diez funciones extensas fundamentalmente consultivas. La frecuencia de reunión es limitada -un par de veces al año- lo que deja poco margen de eficacia a este organismo. La primera función es la de "asesorar al departamento" correspondiente (al DCMU). La pauta es otra vez del Gobierno asesorando al Gobierno. Las funciones son asesorar, informar, facilitar, impulsar, promover, fomentar, y conocer. La última de las funciones previstas en la ley es la de "proponer los criterios de la política de becas que garanticen una igualdad de oportunidades efectiva" (artículo 128.j). Todo lo relativo a becas y su financiación en la LUC está difuminado y es ambiguo, con lo que nadie parece ser responsable de su inexistencia e inoperatividad.

La Junta es supuestamente el órgano de gestión del CIC, pero el CIC no es un órgano de gestión. Hay un Pleno de la Junta que integra un 17\% de miembros de universidades privadas. Para evitar conflictos de competencias públicas/privadas, está la Junta Permanente que tiene solamente un 5\% de miembros de universidades privadas (un miembro es de la UOC, el rector) ${ }^{19}$. La diferencia entre ambas juntas es mínima, y más bien la existencia de dos organismos que son $88 \%$ iguales supone un engorro de organización poco efectivo. Hay que tener en cuenta que la mayoría de los miembros de ambas juntas están nombrados a dedo por la Generalitat: $54 \%$ del Pleno de la Junta y $62 \%$ de la Junta Permanente. Para evitar el absentismo de las dos juntas la ley establece que la asistencia no sea delegable. Son organismos manejables -de 24 y 21 miembros en total- lo que hace más operativo su funcionamiento. El artículo 131 presenta las catorce "funciones de la Junta" sin establecer las que se refieren al pleno y las de la permanente. Ambas juntas mantienen una función similar a la Conferencia General, dedicadas a proponer, infor- 
mar, conocer, articular, elaborar propuestas, e impulsar. La única función ejecutiva es que nombra los representantes de las universidades públicas en otros organismos. Respecto de las universidades privadas se informa su programación. A pesar de que el CIC es un organismo dominado por el Gobierno de la Generalitat, para evitar algún tipo de problema, la LUC explicita que: "Los informes del Consejo Interuniversitario de Cataluña son preceptivos, pero son sólo vinculantes si una disposición normativa expresa lo establece" (artículo 132.3). Es una fina distinción burocrática cuyo significado real no está claro.

\section{Evaluación}

Así como el Consejo Interuniversitario de Cataluña es un organismo mimético del Consejo de Coordinación Universitaria, la Agencia para la Calidad del Sistema Universitario de Cataluña se establece como alternativa a la Agencia Nacional de Evaluación de la Calidad y Acreditación. Ya se ha dicho que el concepto de "sistema universitario" es realmente una ficción, por lo que en adelante se cita como "Agencia para la Calidad". Evaluación, calidad, excelencia, acreditación y certificación son algunos de los conceptos de moda en el sector universitario español. Se habla con insistencia de "indicadores de calidad", pero los organismos públicos no han sido capaces de definir un conjunto claro de indicadores de excelencia. ${ }^{20}$ La LUC crea la Agencia para la Calidad pero no se posiciona sobre los temas de fondo de la calidad y la excelencia.

Para crear la Agencia se utiliza la figura existente del consorcio creado en el año 1996, cuya productividad fue bastante limitada. La LUC incluye una larga lista de dieciocho funciones de la nueva Agencia para la Calidad, que supone evaluarlo todo: centros, enseñanzas, docencia, investigación, actividades, programas, servicios y gestión. Además, se dedica supuestamente a educar, estudiar e informar. Tanta casuística de funciones esconde la indefinición de esa Agencia. Es otro de los organismo que se dedica a controlar a las once universidades. No es fácil diferenciar las funciones entre la Agencia y el CIC, e incluso con referencia a los Consejos Sociales de las Universidades. Las funciones parecen diseñadas por la propia Agencia, que se ha extralimitado en controlarlo todo. Eso puede suponer un coste económico considerable. Incluso piensa evaluar la actividad investigadora de todo el profesorado de las universidades privadas. A pesar de que se supone que es un organismo externo (ise puede realizar evaluación adecuada que no sea externa?) incluye un artículo que entre sus funciones señala "las tareas que le sean encargadas por el departamento" de Universidad. También hay un cajón de sastre que supone "el resto de funciones que le atribuyen esta Ley, sus estatutos y otra normativa vigente". No es aceptable que un organismo que se supone externo al Gobierno pueda definir sus funciones respecto de las once universidades en sus propios estatutos. El papel legal de la Agencia es ambiguo, pues es una entidad de Derecho público "que ajusta su actividad al Derecho privado". Si es privada su función de recabar información del sistema público es (o debería ser) limitada. Además, la LUC obliga a las universidades privadas a formalizar convenios con la Agencia, lo que en la práctica supone pagar obligatoriamente por esos servicios. La indefinición, así como los problemas de privacidad del personal y las instituciones, van a ser temas polémicos en la aplicación de esta todopoderosa Agencia para la Calidad dentro de la Comunidad Autónoma. Pero el problema de fondo es que la LUC no define calidad, ni presenta ideas para adaptar ese concepto a la Universidad catalana. Lo que hace es dar poder (demasiado, en mi opinión) a un organismo semiprivado, sin saber cómo lo organiza, ni lo qué va a costar, ni quién va a pagar por ello.

La explicación de esa aparente contradicción es que realmente es un organismo nombrado a dedo por el propio Gobierno de la Generalitat: nombra la presidencia, la dirección, el 59\% por ciento de los miembros del Consejo de Dirección, y todos los presidentes de las comisiones. No queda claro porqué es un organismo bicéfalo: con un presidente y un director al mismo tiempo. El presidente -nombrado por el Gobierno de la Generalitat "entre personalidades de reconocido prestigio en el ámbito universitario"- lo es al mismo tiempo de la Agencia y del Consejo de Dirección. Es además por tiempo indefinido (cuatro años siempre renovables) lo que es poco conveniente. Los miembros del Consejo de Dirección son 27, pero el 67\% de ellos son además miembros del CIC. ${ }^{21}$ No se entiende que se diseñen organismos que en la práctica son tan solapables, pues suponen un nivel de endogamia e inoperatividad alto. Además los miembros pueden serlo por doce años, lo que parece un periodo excesivamente largo, casi siempre nombrados de forma directa. ${ }^{22}$ En cualquier caso el Consejo de Dirección sólo se reúne dos veces al año, lo que sugiere que es poco operativo. El poder reside pues en las dos cabezas: presidente y director.

El director/a es designado por el Consejero de Universidad, una vez oído el Consejo de Dirección (en que el 59\% de los miembros están nombrados por el mismo Consejero) para cuatro años, pudiendo estar en el puesto hasta doce años. "Oír al Consejo" es pues otro de los círculos viciosos de la LUC. Bajo su dirección se establecen al menos tres comisiones: de Evaluación de la Calidad, de Profesorado Lector y Colaborador, y de Evaluación de la Investigación. En la comisión de Evaluación de la Calidad todos los miembros son nombrados a dedo por el director, quien a su vez ha sido nombrado directamente por el Gobierno de la Generalitat. No parece ser éste un sistema de eva- 
luación ortodoxo. La comisión de Profesorado Lector y Colaborador se entiende que es sobre estos dos tipos de profesorado, tiene un presidente propio que es nombrado por el Consejero de Universidad (ni siquiera por el de la Agencia) que a su vez elige a dos personas más; y es el Consejo de Dirección el que escoje a los cinco miembros restantes "a propuesta del presidente o presidenta de la comisión". Es pues una comisión que depende fundamentalmente de una persona de confianza del Gobierno, con un sistema de selección endogámico. Es una comisión pequeña, de apenas ocho personas, el 100\% elegidas directa 0 indirectamente por el Gobierno de la Generalitat. La comisión de Evaluación de la Investigación es la más numerosa, con 21 miembros. Su presidente es nombrado directamente por el Consejero de Universidad, quien elige además otros cuatro miembros. El resto, dieciséis, son designados por el Consejo de Dirección pero a propuesta del presidente de la comisión, quien a su vez ha sido elegido por el Consejero. Este sistema difícilmente supone una evaluación externa adecuada, y no es políticamente independiente. Afortunadamente, los elegibles tienen que ser catedráticos con 24 años de actividad investigadora reconocida (cuatro sexenios) lo que les sitúa en una edad en torno a los sesenta años. En el caso de que eso no sea posible se pueden nombrar personas que tengan la Medalla Narcís Monturiol (sic). Esta última comisión se divide a su vez en comisiones cuya variedad y tamaño no aparece bien descrito en la ley.

La LUC en su artículo 148.2 señala: "Las evaluaciones y acreditaciones hechas por otras agencias u órganos de evaluación en materia de la competencia de la Agencia para la Calidad del Sistema Universitario de Cataluña, podrán ser consideradas por la citada Agencia, a los efectos de lo que establece esta Ley". ¿o es al revés? Si se compara este artículo con el número 31 (también el artículo 32) de la LOU la responsabilidad básica reside en la Agencia Nacional de Evaluación de la Calidad y Acreditación (ANECA); y la responsabilidad subsidiaria corresponde a la Agencia para la Calidad de la Comunidad Autónoma. En cualquier caso la LUC ni siquiera cita expresamente a la ANECA en su articulado. La redacción de la LUC es además confusa y ambigua. Sería necesario que se estableciesen bien las responsabilidades de ambas agencias en el contexto de Cataluña pues legalmente no está claro: LOU y LUC dicen cosas distintas. ${ }^{23}$ Otro aspecto interesante es la financiación de la Agencia de Calidad, que cuenta con "los ingresos derivados del ejercicio de su actividad". No queda claro si el profesorado que es evaluado debe pagar por ello, o si son las universidades las que pagan. Tampoco se sabe cuánto van a pagar. Lo evaluación no es externa, y además parece que hay que pagarla.

El diseño de la Agencia para la Calidad debería transformarse, convirtiéndose en un organismo mucho menos gubernamental, más externo, con nociones más claras de lo que es "calidad", y que no se solape (67\% de sus miembros actualmente) con otros organismos como el CIC. Las Comisiones no pueden ser nombradas de forma endogámica (100\% de sus miembros son elegi- dos directa o indirectamente por la Generalitat). No hay suficientes personas en Cataluña para ocupar tantos puestos a dedo, durante ese tiempo, y con un poder tan excesivo.

\section{Financiación de universidades públicas}

La decena de artículos (155 a 165) con los que finaliza la LUC, relativos a patrimonio, contratación, y presupuesto no ofrecen novedades respecto de la LOU. La referencia a la LOU es continua. Dos meses antes de cada año fiscal las universidades tienen que comunicar oficialmente al Gobierno de la Generalitat la previsión ("agregada" se señala) de las plazas de cuerpos docentes e investigadores, y de las plazas de contratados que se piensan convocar durante el año siguiente. Esto supone poca autonomía de cada universidad para ir variando su dotación de profesorado y personal investigador conforme a las necesidades. La razón es que los costes de personal docente, investigador y PAS deben ser autorizados por la Generalitat. La autonomía universitaria es pequeña.

\section{Otras disposiciones}

La LUC incluye una docena de disposiciones adicionales, algunas de las cuales merecen un comentario sociológico. La disposición $4^{\mathrm{a}}$ se refiere a la creación de la Oficina sobre el Espacio Europeo de Enseñanza Superior cuya organización se propone dentro del CIC. Sus funciones son las esperables de ayudar a adaptar las universidades al sistema de ciclos (se entiende de dos ciclos), y promover la movilidad. No se realiza ninguna referencia al cumplimiento de los planes que se proponen desde el Ministerio de Educación, ni a la coordinación con otras Comunidades Autónomas ${ }^{24}$.

La UOC requiere una disposición $\left(\mathrm{la}_{\mathrm{a}} \mathrm{a}^{\mathrm{a}}\right.$ ) reconociendo explícitamente su condición de universidad impulsada por la Generalitat. Funciona realmente como una universidad pública, pero los precios a los/as estudiantes son privados, lo que significa un nivel de desequilibrio llamativo. La LUC reconoce este estatus especial de la UOC.

La disposición adicional 8a se titula significativamente "perspectiva de género" y merece la pena ser leída entera: "El departa- 
mento competente en materia de universidades y las universidades, han de promover acciones para conseguir la igualdad de oportunidades entre los hombres y las mujeres en todos los ámbitos universitarios". No queda claro si se refiere también a los cargos académicos y a los miembros de las comisiones más importantes: Consejo Social, Consejo Interuniversitario, Agencia para la Calidad, Comisiones de evaluación, así como en las plazas de profesores agregados y catedráticos contratados permanentes. Habrá que comprobar si la Generalitat y las universidades catalanas realizan algún progreso en esa dirección en los próximos años. Se supone que el proceso de feminización es uno de los más importantes dentro de la consecución de la calidad de las universidades y de su excelencia. Una discusión a fondo del tema aparece en el libro Excelencia: Calidad de las universidades españolas (DE MigueL, CAïs, VAQUERA 200125 ${ }^{25}$. La Institución Catalana de Investigación y Estudios Avanzados (ICREA) en la disposición adicional 10a tiene una referencia a la vinculación de investigadores.

La LUC incluye también siete disposiciones transitorias. La $4^{\mathrm{a}}$ es importante, pues vuelve a uno de los temas peor tratados en la LUC que es el de ayudas económicas a los/as estudiantes. Se refiere al artículo 41 (ya comentado antes) que propone el desarrollo futuro de una política de créditos y becas, siguiendo el artículo 45 de la LOU. En el segundo apartado de ese artículo, la LOU señala que "el desarrollo, ejecución y control del sistema general de becas y ayudas al estudio corresponde a las Comunidades Autónomas en sus respectivos ámbitos de competencia y en colaboración con las Universidades". La disposición transitoria de la LUC marea un poco más el tema señalando: "Mientras no se haga efectiva la transferencia de funciones y servicios del estado en materia de becas, la plena efectividad de lo dispuesto en el artículo 41 de esta Ley se producirá a partir de la asunción por parte de la Generalitat de Cataluña de la correspondiente transferencia de funciones y servicios del Estado en esta materia". Cada persona puede interpretar lo que quiera con esta ambigua declaración de intenciones. La realidad es que no hay una política de becas en Cataluña, y que esa Comunidad Autónoma es una de las que más necesita en España de una política de ayudas económicas a estudiantes, debido al desequilibrio social en la matrícula universitaria. No hay en la LUC un planteamiento claro sobre este tema de becas, ayudas, y préstamos; y esta disposición transitoria parece otra táctica de retraso en asumir la responsabilidad. Hubiese sido más eficiente derivar el incremento de presupuesto hacia becas de estudiantes que a salarios de profesores.

La disposición transitoria $7^{\text {a }}$ ya ha sido comentada. Son las excepciones a la regla de los dos años de desvinculación respecto de la universidad donde se desea obtener una plaza de profesor/a. Anula así al artículo 47 en el caso de ayudantes, profesores asociados, o los cuatro cuerpos de funcionarios.

La disposición derogatoria deja inactivos siete textos legales, promulgados desde 1984 hasta el año 2000.
Algún tema importante se reserva para las tres disposiciones finales. La $1^{\text {a }}$ vuelve a remachar que la Generalitat va a impulsar la convergencia plena con Europa en el horizonte del año 2010.

La disposición final 2a promete un incremento sustancial del presupuesto de la Generalitat para las universidades públicas. Sin embargo la forma en que está escrita es algo confusa: "los presupuestos de la Generalitat han de aumentar la dotación asignada a la financiación de las universidades públicas, dentro del periodo 2003-2010 y de manera gradual, hasta llegar a un incremento real minimo del $30 \%$ de la dotación presupuestada para el 2002". Si la interpretación es correcta, eso supone que en el año 2010 el presupuesto de la Generalitat para las universidades públicas -no para otros gastos de enseñanza superior o de gestión de la política universitaria- serían al menos un 30\% más elevado que la dotación de ocho años antes. No queda claro si se está hablando de euros constantes o no. Tampoco aclara si es una dotación per capita (por estudiante) o no. En estos ocho años la Comunidad Autónoma debería incrementar al menos un 50\% la proporción de población estudiantil universitaria. Así que el incremento del 30\% parece insuficiente. Incluso si se mantiene la tasa de estudiantes -lo que supondría un fracaso de la política universitaria en Cataluñano es un crecimiento excesivo; y si se calcula en euros corrientes puede resultar una disminución relativa de recursos. La promesa la realiza un partido político conservador en el Gobierno de la Generalitat a las puertas de unas elecciones autonómicas en que luego se producen cambios fundamentales. El incremento de gasto es más wishful thinking que otra cosa. Tampoco se especifica -no es este el lugar- de dónde se piensa detraer ese incremento de gasto en universidades, es decir, de qué otras partidas del presupuesto.

Esta disposición incluye también la promesa de la cantidad total de los nuevos tipos de profesores contratados, permanentes. La Generalitat se compromete a dotar presupuestariamente un plan que incluya la creación de 400 "catedráticos" contratados y 800 profesores "agregados" en doce años. Especifica que serían aproximadamente cien al año entre catedráticos y agregados. Pero la Generalitat no financia todo ese profesorado, sino solamente al 50\%. Esta figura de co-financiación supone que las universidades respectivas son las que aportan el 50\% restante. La LUC se compromete también a que este incremento presupuestario aparezca en los presupuestos de la Generalitat a partir del año 2003. Ya se mencionó antes que cien profesores al año, entre siete universidades públicas (si se incluyen Vic y UOC serían ya nueve), son apenas cuatro o cinco catedráticos, y siete a diez profesores agregados, por universidad cada año. Es una cantidad realmente baja para lograr una transformación del sistema de estratificación actual del profesorado. Incluso supone un sistema más desigual y estratificado que la pirámide actual de profesorado funcionario. 


\section{Escenarios posibles}

De la ley a la realidad suele haber grandes diferencias ${ }^{26}$. La Ley de Reforma Universitaria (LRU), por ejemplo, se concibió en 1983 como una ley modernizante y progresista. Pero terminó siendo inoperativa y endogámica. ¿̨or qué? Porque la realidad no se cambia con leyes fácilmente. La LOU de 2001 trata de resolver problemas graves (como la endogamia del profesorado o la descoordinación de recursos). Deja a las Comunidades Autónomas solucionar otros problemas a nivel local. La LUC no soluciona problemas locales, sino que se dedica a copiar miméticamente la estructura organizativa estatal, creando organismos paralelos como el CIC y la Agencia de Calidad, estructurando una especie de Ministerio de Educación Superior. La LUC se puede topar con escenarios reales problemáticos. Un buen ejercicio de crítica científica es imaginar algunos de esos escenarios posibles. No necesariamente van a producirse, o no todos a la vez, pero conviene estar preparados/as.

1. El sector universitario catalán puede terminar siendo un sistema estatalizado, configurándose como una alternativa a la Administración central, y no con el deseo real de ampliar la educación postsecundaria a la mayor parte de la población. El desarrollo de la Universidad en Cataluña depende de la suerte de tener un Gobierno autonómico progresista -no uno conservador y agotado políticamente como el que redacta la ley- y no tanto de la LUC. El sector universitario que se propone, supone que el Gobierno de la Generalitat domina no sólo el sector universitario sino además todas las universidades públicas. Eso puede suponer una estrategia política útil en el enfrentamiento con la Administración central, lo que le permite regatear fondos y otros recursos. Pero la consecuencia indeseable es el retraso en el desarrollo de la educación universitaria en Cataluña.

2. El modelo que se propone puede producir un debilitamiento de la autonomía de las universidades. En el afán de la Generalitat por controlar todo lo posible, la ley recorta las atribuciones de las universidades, sobre todo a nivel de planificación y dirección. Es cierto que el rector de cada universidad es miembro de numerosos consejos, juntas, y comisiones; pero está en todas partes de forma inoperante. Está en minoría, sin poder controlar la situación. Las decisiones importantes se deciden por las personas elegidas directamente por el Gobierno autonómico. El Gobierno autonómico no es responsable político de las decisiones, puesto que han sido tomadas colegiadamente. Se difumina así la responsabilidad política, y al mismo tiempo se reduce al mínimo la autonomía de las universidades. En otro escenario posible, las diversas organizaciones se convierten en inoperantes, controlándose unas a otras. El Gobierno autonómico, a través de su mayoría en los comités, juntas, agencias, consejos y comisiones -o con su minoría cualificada más la presidencia- puede actuar en forma de veto point neutralizando cualquier acción más que impulsando cambios.
3. El futuro puede suponer el aislamiento universitario de Cataluña. Con esta ley no van a ir a Cataluña estudiantes, ni PAS, ni profesores, ni investigadores del resto de las Comunidades Autónomas españolas. Se puede producir un aislamiento creciente del sector universitario catalán, en contradicción con la colaboración real que existe entre profesionales españoles. Con las condiciones económicas que establece la ley, Cataluña va a contratar pocos profesores o PAS del extranjero. Con el condicionamiento lingüístico tampoco va a atraer estudiantes extranjeros. Es posible un escenario de aislamiento científico de Cataluña. Con una ley como la LUC la mayoría de los mejores científicos de origen no-catalán que trabajan actualmente en Cataluña nunca habrían ido a esas universidades. Se puede dudar igualmente que vayan extranjeros o profesores visitantes si no se ofrece otro tipo de condiciones y recompensas. La ley trata de resolver la endogamia a nivel de profesorado contratado, pero es en sí misma un modelo globalmente endogámico y estatalizado. En consecuencia puede que prevalezca la mediocridad.

4. Al ser una comunidad pequeña, la lucha por privilegios locales va a ser continua y endémica. No hay suficientes personas adecuadas para cubrir tanto cargo en las instituciones que se crean (consejos, comisiones, agencias, juntas, comités, y oficinas); sobre todo no hay gente preparada. Tampoco hay científicos suficientes para evaluar en catalán y de forma imparcial proyectos y acreditaciones desde una posición realmente externa. Es posible que el modelo resultante sea de conflictos continuos, con lealtades e influencias personales (amiguismo, clientelismo, patronazgo) para tratar de conseguir privilegios. Estos conflictos pueden agravarse debido a la creación de la segunda pirámide de profesorado, alternativa a la ya existente de funcionarios, que duplica incluso algún nombre (como el de "catedrático"). La segunda pirámide -la de contratados- es incluso más jerárquica que la ya existente: sólo tiene un 5\% de catedráticos en el año 2015. Los celos, rivalidades y oposiciones entre ambas pirámides pueden ser considerables. Va a ser difícil que la segunda pirámide -la de contratados- no sea vista como compuesta por personas con contactos e influencias a nivel local, pero incapaces de ganar un concurso de habilitación en competición abierta con el resto de profesionales. Puede incluso institucionalizar la mediocridad y generar más conflictos.

5. Se ha desaprovechado la ocasión para organizar una Universidad catalana de calidad para la mayoría de la población (85\% de los/as jóvenes por lo menos). Sólo con la extensión de la Universidad a todas las clases sociales, y a la mayor parte de la juventud, es posible democratizar el sector. Para ello se requiere además un buen sistema de becas. La LUC no compromete recursos para becas a estudiantes, sino para pagar a profesores. El acceso de las clases bajas a la Universidad es un tema que no supone ni una línea en la LUC. Se obvia el avance democrático de la Universidad, desaprovechando un buen momento demográfico para crear un sector universitario avanzado. Esta ley no va 
a solucionar ninguno de los problemas fundamentales del sector universitario: doble presupuesto del actual, expansión numérica y de calidad del PAS, estratificación de universidades, institucionalización y desarrollo de los grupos de investigación (con personalidad jurídica), incremento importante de la tasa de estudiantes becarios, y creación de un doctorado equiparable con el extranjero. En vez de solucionar los problemas importantes la ley se enreda en la creación de más profesorado (un no-problema), produciendo un modelo paralelo alternativo al ya existente, aumentando la jerarquización, y estableciendo instituciones gubernativas para controlar políticamente a las once universidades. El resultado es que el poder pasa del profesorado (fundamentalmente el cuerpo de catedráticos) a ser compartido con el Gobierno de la Generalitat. La estructura general no cambia, sólo se hace más rígida, jerárquica e intolerante.

La LUC tiene los problemas típicos de ser la primera ley autonómica de universidades en España, mostrando niveles de solidaridad y universalismo escasos, y una tendencia a absorber poder (universitario) desde el Gobierno de la Generalitat. Olvida los problemas más importantes de la población que vive en Cataluña. Es quizás una ley con poco impacto social, llamada a ser reformada pronto. El objetivo futuro debe ser la solución de los problemas locales, y crear una Universidad para toda la población, no una copia mimética de la estructura ministerial de España.

\section{Glosario}

ANECA: Agencia Nacional de Evaluación de la Calidad y Acreditación.

apostilla: en inglés a los títulos académicos. También se conoce como "suplemento al título".

AQSUC: Agencia para la Calidad del Sistema Universitario de Cataluña. El Consejo de Dirección tiene 27 miembros, de los cuales el 59\% son elegidos por la Generalitat. El 67\% son además miembros del CIC. Incluye al menos tres comisiones: de Evaluación de la Calidad, de Evaluación de la Investigación (21 miembros), y de Profesorado Lector y Colaborador (8 miembros). La Agencia tiene un presidente y un director.

biciclo: enseñanza universitaria en dos ciclos: graduado (báchelor) y postgraduado (máster/doctorado).

CAAPAU: Consejo de Antiguo Alumnado y de Personas Amigas de la Universidad.

CCU: Consejo de Coordinación Universitaria.
CIC: Consejo Interuniversitario de Cataluña. La Conferencia general tiene 83 miembros $(33 \%$ elegidos por la Generalitat), el Pleno de la Junta tiene 24 miembros (54\% elegidos por la Generalitat). La Junta Permanente 21 miembros (62\% elegidos por la Generalitat) con un solapamiento del $88 \%$ con el Pleno de la Junta.

CiU: Convergencia y Unión, partido catalán (conservador nacionalista) en el poder de la Comunidad Autónoma al aprobar la LUC.

Comisión de Evaluación de la Calidad: de la AQSUC. En la LUC no se define el número de miembros, pero todos son elegidos por la Generalitat.

Comisión de Evaluación de la Investigación: de la AQSUC. Con 21 miembros, todos elegidos por la Generalitat.

Comisión de Profesorado Lector y Colaborador: de la AQSUC. Comisión de 8 miembros, todos ellos elegidos por la Generalitat.

comunidad universitaria: eufemismo para referirse a personal académico, PAS y alumnado.

concurso de acceso: proceso de selección de profesorado en una universidad concreta establecido por el Real Decreto de Cuerpos de Funcionarios Docentes Universitarios 774/2002 (de julio 2002).

Conferencia General: del CIC, es un organismo de 83 miembros (33\% elegidos por la Generalitat) que se reúne dos veces al año.

Consejo de Antiguo Alumnado y de Personas Amigas de la Universidad: un miembro pertenece al Consejo Social.

Consejo Interuniversitario de Cataluña: también CIC, organismo que coordina la política universitaria, y que incluye una Conferencia General (83 miembros), el Pleno de la Junta (24 miembros) y la Junta Permanente (22 miembros).

Consejo Social: de la universidad, con 15 miembros, el 40\% elegidos por la Generalitat.

cuerpos docentes: son cuatro cuerpos de funcionarios, de catedráticos de universidad, profesor titular de universidad, catedrático de escuela universitaria, y profesor titular de escuela universitaria. Por ley deben ser el 50\% del profesorado de cualquier universidad. De los cuerpos relativos a escuelas universitarias ya sólo se convocan plazas en el 6\% de las 187 áreas de conocimiento.

CSIC: Consejo Superior de Investigaciones Científicas.

DCMU: departamento de la Generalitat competente en materia de universidades. Circunloquio utilizado en la LUC para referirse al Departamento futuro de la Generalitat con responsa- 
bilidades en la educación universitaria. Actualmente es el DURSI. Está dirigido por un Consejero que a su vez es miembro del Gobierno de la Generalitat.

\section{DOGC: Diari Oficial de la Generalitat de Catalunya.}

DURSI: Departamento de Universidades, Investigación y Sociedad de la Información, de la Generalitat, sito en la Via Laietana 33. Está dirigido por un Consejero.

EAHE: European Area of Higher Education, iniciada en 1999 con el Tratado de Bolonia.

ECTS: también denominado crédito europeo, European Credit Transfer System.

EEES: Espacio Europeo de Enseñanza Superior, traducción de European Area of Higher Education. La traducción más acertada (y correcta políticamente) sería "Área Europea de Educación Terciaria”.

ERC: Esquerra Republicana de Cataluña, único partido que votó favorablemente la LUC junto con CiU.

Estatutos: normalmente de una universidad.

FPI: formación de personal investigador.

Generalitat: gobierno de la Comunidad Autónoma de Cataluña.

habilitación: proceso de selección de profesorado a nivel nacional (español) establecido por el Real Decreto de Cuerpos de Funcionarios Docentes Universitarios 774/2002 (de julio 2002).

I+D: investigación y desarrollo.

ICREA: Institución Catalana de Investigación y Estudios Avanzados.

investigador: hay cuatro tipos: investigador, investigador postdoctoral, investigador vinculado, e investigador contratado por obra o servicio.

Junta: Del CIC. Puede ser el Pleno o la Permanente.

lengua oficial de la Universidad: catalán y castellano (artículo 6 de la LUC).

LOU: Ley Orgánica de Universidades 6/2001, en el BOE 307, del 24 de diciembre 2001. Contiene 89 artículos.

LRU: Ley de Reforma Universitaria, del gobierno socialista en 1983.

LUC: Llei d'Universitats de Catalunya, aprobada el 19 de febrero de 2003. Tiene 165 artículos y 23 disposiciones.

MCYT: Ministerio de Ciencia y Tecnología.

MEC: Ministerio de Educación y Ciencia.
MECD: Ministerio de Educación, Cultura y Deporte.

medalla Narcís Monturiol: mérito con el que se puede pertenecer a la Comisión de Evaluación de la Investigación de la Agencia para la Calidad.

Oficina Europea: oficina sobre el espacio europeo de enseñanza superior, dentro del CIC.

PAAU: pruebas de aptitud para el acceso a la universidad.

PAS: personal de administración y servicios.

penene: profesor/a no numerario.

PIO: principio de igualdad de oportunidades.

PRC: Plan de Investigación de Cataluña. El tercero abarca del año 2001 al 2004.

profesor de Universidad: hay catorce tipos: catedrático de universidad, profesor titular de universidad, catedrático de escuela universitaria, profesor titular de escuela universitaria, catedrático (contratado), profesor agregado, profesor colaborador permanente, profesor lector, profesor colaborador temporal, profesor asociado, profesor visitante, profesor emérito, profesor honorario, y ayudante.

regla de los dos años: de no vinculación con la universidad a cuya plaza se concursa.

sexenio: periodo de actividad investigadora reconocido, también denominado "tramo".

SGIB: Standing Group on Indicators and Benchmarks de la Comisión Europea.

sistema universitario: eufemismo para referirse al sector universitario. No es realmente un sistema, ni funciona como tal.

terciaria: término correcto para la llamada "enseñanza superior" que incluye la universitaria. A veces denominada postsecundaria.

UAB: Universidad Autónoma de Barcelona (en Bellaterra, Barcelona), creada en 1968, tienen unos 39.000 estudiantes.

UB: Universidad de Barcelona, creada en 1450, tiene 65.000 estudiantes.

Universidad: (en mayúsculas) conjunto de todas las universidades de la Comunidad Autónoma. En estos momentos son once: siete públicas, dos semiprivadas, y dos privadas (católicas las dos).

Universidad de Girona: creada en 1991 tiene unos 13.000 estudiantes.

Universidad de Lleida: creada en 1991 tiene 11.000 estudiantes. 
Universidad de Vic: fundada públicamente en 1997 pero de carácter privado, tiene alrededor de 3.000 estudiantes.

Universidad Internacional de Cataluña: universidad privada y católica, creada en 1997, con 1.300 estudiantes.

Universidad Ramon Llull: privada, católica, creada en 1991, tiene unos 13.000 estudiantes.

Universidad Rovira i Virgili: en Tarragona, creada en 1991, tiene aproximadamente 13.000 estudiantes.
UOC: Universitat Oberta de Catalunya, Universidad Abierta de Cataluña.

UPC: Universidad Politécnica de Cataluña (fundamentalmente en Barcelona), creada en 1971, tiene unos 37.000 estudiantes.

UPF: Universidad Pompeu Fabra (en Barcelona), pública, creada en 1990, tiene 9.000 estudiantes.
* Catedrático de Sociología, Universidad de Barcelona, jesusdemiguel@ub.edu.

${ }^{1}$ Muchas gracias a la lectura detallada realizada por Andreu Mas-Colell. Gracias también a Marga Marí-Klose y a Jara D. Sánchez Bennasar. Una versión al día de este texto se puede conseguir a través del correo electrónico jesusdemiguel@ub.edu o escribiendo a Jesús M. de Miguel, Departamento de Sociología, Universidad de Barcelona, Avenida Diagonal 690, 08034 Barcelona, tel. 932034531.

${ }^{2}$ Ley 1/2003 de 19 de febrero, Diari Oficial de la Generalitat de Catalunya 3.826 (20 febrero 2003). La LUC aparece firmada por Jordi Pujol como Presidente de la Generalitat, y por Andreu Mas-Colell como Consejero de Universidades, Investigación y Sociedad de la Información (19 de febrero de 2003).

3 Se incluye un glosario al final.

4 Una visión global puede verse en Jesús M. DE Miguel, "Política de Universidad: Escenarios futuros" Revista de Estudios Políticos 122 (2003), pp. 33-72.

${ }^{5}$ Las once universidades se pueden consultar en la red: dursi.gencat.es. En el caso de las universidades Ramon Llull e Internacional de Cataluña el DURSI deja claro que son privadas; pero no en el caso de la UOC ni en la Universidad de Vic que tienen un estatus más ambiguo: su origen es público pero su gestión es privada. El DURSI las presenta sin un orden aparente: Universitat de Barcelona, Universitat Autònoma de Barcelona, Universitat Politècnica de Catalunya, Universitat de Girona, Universitat de Lleida, Universitat Pompeu Fabra, Universitat Rovira i Virgili, Universitat Oberta de Catalunya, Universitat Ramon Llull, Universitat Internacional de Catalunya, y Universitat de Vic.

${ }^{6}$ Realising the European Higher Education Area, Communique of the Conference of Ministers responsible for Higher Education in Berlin on 19 September 2003, 9 pp., como parte del Bologna Process cuya tercera reunión de ministros es la de Berlín 2003. Ver un análisis en Jesús M. DE Miguel, El Proceso de Bolonia (Barcelona: Universidad de Barcelona, diciembre 2003), 22 pp.

7 "La clase alta tiene cinco veces más posibilidades de ir a la Universidad" El País (9 mayo 2003), sección "Cataluña”, pp. 1 y 9. El título de la página 9 es "El nivel cultural de las familias es más determinante que el cambio".

8 Jesús M. DE Miguel, Elizabeth Vaquera, y Haizam Amirah, "Sobran o faltan doctores?" (Barcelona: Departamento de Sociología, Universidad de Barcelona, marzo 2003), 33 pp., manuscrito, presentado como ponencia en el Congreso de Sociología Catalana, en Reus (2003). Publicado en Empiria, Revista de Metodología de Ciencias Sociales 7 (2004), pp. 115-155.

9 Eulalia Vintró señala: "En el caso de la LUC, la indefinición y la ambigüedad predominan [...] De eso tan catalán que es el dinero no se habla". Caracteriza la LUC como "una ley de universidades reglamentista, con más de ciento ochenta prescripciones entre artículos y disposiciones, cincuenta más [en realidad 58] que la ley española. Parafraseando el dicho 'cuando no se quiere resolver un problema, se crea una comisión', podríamos afirmar 'cuando un gobierno no quiere resolver un problema, hace una ley', con la falsa expectativa de que la complejidad se difuminará y hasta será resuelto por el encantamiento de la ley. La realidad, sin embargo, es muy tozuda y desde la Ley general de educación del año 1970 todo el mundo sabe que si las leyes no van acompañadas de una financiación específica y adecuada, los objetivos no sólo se convierten en papel mojado, sino una cosa más grave, generan frustración, inmovilismo y desencantamiento" Eulalia VINTRÓ (Profesora de Filología Griega de la Universidad de Barcelona), "Llei d'universitats de Catalunya", Enxarxa't: Revista de la Xarxa de Dinamització Lingüistica de la UB 1 (invierno de 2002), difusión gratuita, Universidad de Barcelona, pp. 4-5.
10 Se trata del gobierno de Convergencia y Unión que dura hasta diciembre de 2003, en que es sustituido por un "gobierno tripartito" del Partit Socialista de Catalunya, Esquerra Republicana, e Iniciativa per Catalunya.

11 Este aspecto se llevó al Tribunal Constitucional.

12 No debería aquí haber utilizado la expresión "ciudadano", sino población.

13 Un ejemplo de contenido innecesario para una ley autonómica: "La docencia de doctorado, que se puede impartir en los departamentos, centros e institutos universitarios, corresponde a doctores. Los programas de doctorado aprobados por cada universidad o conjunto de universidades, tienen un director que ha de ser un profesor o profesora doctor de la universidad coordinadora del programa" (artículo 12.3).

$14 \mathrm{El}$ modelo catalán es incluso más elitista.

15 Las comisiones de acceso que se reglamentan (artículo 148.2) en los Estatutos de la Universidad de Barcelona son de cinco miembros: el presidente que es elegido directamente por el rector, dos miembros por el Departamento, y los otros dos por el centro (Facultad o Escuela). En la práctica eso supone que en muchos casos los cinco miembros de la comisión de acceso son elegidos por el candidato/a local.

${ }^{16}$ La prensa presenta el programa de profesorado como una adición de profesores. El Pais titula por ejemplo (13 febrero 2003, Cataluña, p.1): "La ley de universidades crea un cuerpo docente dependiente de la Generalitat. Aprobado el marco legal de la enseñanza superior catalana sólo con los votos de CiU y ERC". La fórmula del $50 \%$ tiene dos implicaciones: representa una inyección de recursos económicos en la Universidad. Dado que las universidades tienen que financiar el otro $50 \%$ la oferta de contratos se va a compensar en parte con las jubilaciones o con las plazas que queden vacantes para promoción. Es pues un programa para reorganizar la estructura de profesorado en dos pirámides (en vez de una) pero no necesariamente para incrementar la tasa global de profesorado.

17 Esto es mucho prometer en el caso de un Gobierno autonómico (de Convergencia y Unión) que en el año 2003 se encuentra en fase pre-electoral, con serias dificultades para seguir en el Gobierno. En diciembre de 2003 pierde el Gobierno. La promesa de doce años involucra pues a futuros gobiernos autonómicos, que no han votado a favor de la LUC (únicamente votada por $\mathrm{CiU}$ y ERC) con lo que debe tomarse con reservas. El nuevo responsable de universidades es Carles Solè.

${ }^{18}$ En una primera versión de la ley se pensó en pagar más a los/as profesores que enseñaran en catalán; pero esta medida luego se desestimó.

${ }^{19}$ En diversos artículos de la LUC se equipara la UOC con una universidad pública. 20 Ver Jesús M. De Miguel, Jordi Caïs, y Elizabeth VAquera, Excelencia: Calidad de las universidades españolas (Madrid: Centro de Investigaciones Sociológicas, Ministerio de la Presidencia, 2001), 506 pp. El estudio exhaustivo de indicadores de calidad está realizado entre la Universidad de Barcelona y la University of Pennsylvania.

${ }^{21}$ Los rectores están en todas partes, en todos los comités diseñados en la LUC, y además no se permite la delegación. Lo que supone que los rectores sólo van a estar yendo a reuniones, sin tener quórum suficiente para tomar decisiones. En Cataluña, el poder de los rectores va a quedar neutralizado, o incluso bastante disminuido.

22 El que sean nombrados por cuatro años, justo antes de las elecciones en la Comunidad Autónoma, supone además una cristalización peculiar de este organismo.

23 Este es un tema que contribuyó al apoyo de CiU a la votación a favor de la LOU en el Parlamento español a finales del año 2001.

${ }^{24}$ Ministerio de Educación, Cultura y Deporte, La integración del sistema universitario español en el Espacio Europeo de Enseñanza Superior (Madrid: MECD, febrero 
2003), 22 pp. Ver, también, Andreu Mas-Colell, "En Europa, tres es más que cuatro", El País (10 marzo 2003) publicado en la sección Aula Libre.

25 Ver también Elizabeth Vaquera, y Jesús M. DE Miguel, "Mujeres en la torre de marfil: Feminización de la universidad española" Gestión y Administración de Politicas
Públicas 22 (2001), pp. 63- 80 publicado en mayo 2003. Presenta datos y objetivos para Cataluña.

26 Ronald G. EhrenberG, ed., Governing Academia (Ithaca: Cornell University Press, 2004), $320 \mathrm{pp}$. 